http://dx.doi.org/10.18232/alhe.1048

Artículos

\title{
Pueblos y trabajo indígena en los Andes centrales: Bombón en el siglo XVII
}

\section{Towns and Indian Labor in the Central Andes: Bombon in the Seventeenth Century}

Francisco F. Quiroz ${ }^{1, *}$ * 0000-0003-2662-9272

${ }^{1}$ Universidad Nacional Mayor de San Marcos, Lima, Perú.

*Correspondencia: fquirozc@unmsm.edu.pe

Resumen. Con base en una documentación rica e inédita, este artículo busca establecer los cambios en las relaciones laborales de los pueblos de indios o reducciones con el surgimiento y consolidación de estancias ganaderas y obrajes privados en las inmediaciones, y la disminución drástica de la población indígena en la meseta de Bombón entre 1667 y 1677 (Andes centrales). Se discuten temas de la historia laboral vigentes en la historiografía peruana y latinoamericana como el trabajo libre y el compulsivo, la mita, el yanaconaje, el peonaje y las reducciones o pueblos de indios. Este estudio encuentra que en las nuevas condiciones los pueblos de indios siguen siendo importantes, pero, con la aparición de mecanismos coercitivos individuales, han dejado de ser imprescindibles para reclutar, retener y remunerar a los trabajadores de las haciendas y el obraje.

Palabras clave: trabajo servil y libre; reducciones indígenas; haciendas; obrajes.

Abstract. Based on unpublished and rich documentation, the article seeks to establish the changes in labor relations of Indian towns (reducciones) with the emergence and consolidation of ranches and sweatshops (obrajes) in their vecinity and the drastic demographic decrease in the Peruvian central Andes (Bombon

CÓMO CITAR: Quiroz, F. F. (2020). Pueblos y trabajo indígena en los Andes centrales: Bombón en el siglo XVII. América Latina en la Historia Económica, 27(2), 1048. DOI: 10.18232/alhe.1048 
plateau) between 1667 and 1677. The article discusses current labor history topics in Peruvian and Latin American historiography, such as free and coercive labor, mita, yanaconaje, peonage and Indian towns or reducciones. This study finds that -with the emergence of individual means of coercion- in the new conditions Indian towns continue being important but they are no longer essential in the recruitment, retention and remuneration of the workers of the estates and the obraje.

Key words: free and servile labor; Indian reductions; haciendas; obrajes.

JEL: F54; N16; N36; N56; N86.

Recibido: 21 de diciembre de 2018.

Aceptado: 21 de febrero de 2019.

Publicado: 21 de diciembre de 2019.

Organismo patrocinador: Universidad Nacional Mayor de San Marcos (Grupo de Investigación Historia Económica y Social), Perú.

\section{INTRODUCCIÓN}

Este estudio discute el cambio ocurrido en la segunda mitad del siglo Xvir en los pueblos de indios creados en el siglo anterior por la administración colonial en los Andes por el virrey Francisco de Toledo (1569-1581). Con base en documentación privilegiada 11 obtenida en la sección Socorros de Indios del Archivo Arzobispal de Lima (AAL), presento las cambiantes condiciones de trabajo de los habitantes de quince pueblos o reducciones en cuatro estancias ganaderas y un obraje textil en la meseta de Bombón, en torno al lago Chinchaycocha o Junín (4 080 metros sobre el nivel del mar) en los Andes centrales entre los años 1667 y 1677. El caso de Bombón no debió ser muy diferente a la experiencia de otras provincias, que ignoramos por carecer de fuentes documentales y estudios concretos, y que podría ser ilustrativo para el estudio de otros casos.

La documentación es una sólida base empírica que permite establecer un cambio muy profundo en las relaciones laborales en la meseta de Bombón y, por extensión, en los Andes centrales. No parece tratarse de una coincidencia. La década en estudio (1667-1677) muestra el paso de un sistema toledano de mitas para abastecer de mano de obra a las empresas privadas (haciendas, obrajes, minas, etc.) bajo un régimen de solidaridad corporativa a otro que combina lo anterior con la captación y retención individual de trabajadores. Es decir, los pueblos y curacas ya no son

\footnotetext{
${ }^{1} \mathrm{El}$ corpus documental es privilegiado tanto por el contenido de la información como por las condiciones de su conservación. Los archivos históricos no guardan, por lo regular, documentación de origen privado. Una excepción son los papeles confiscados a los jesuitas al momento de su expulsión en 1767 y que conforman los fondos de Temporalidades que hasta hace poco tiempo han sido la principal fuente para el estudio de haciendas, obrajes, escuelas, etc. Al parecer, el corpus documental se reúne a la muerte del empresario Andrés López Grayño y queda en un archivo eclesiástico, por ser el dueño un sacerdote, para un posible proceso judicial sobre la herencia del importante legado. No he encontrado el juicio que, probablemente, se siguió sobre este caso en el fuero eclesiástico o civil. Por otro lado, se han conservado 19 libros mayores, aunque sólo cuatro están más o menos completos; contienen las cuentas del empresario del complejo ganadero y obrajero en la meseta de Bombón entre 1667 y 1677 sobre el trabajo de los mitayos y alquilados, indicando los pueblos de origen, las parcialidades a las que pertenecían, los montos trabajados, las deudas en que incurrían. Los libros conservados son nominalmente anuales, pero las cuentas se prolongaban por varios años. Aun así, las referencias se hacen sobre los años de los libros mayores y, en particular, sobre los documentos correspondientes a los años 1667 , 1669, 1671, 1674 y 1677 que ilustran la situación de la década estudiada. Se debe aclarar, sin embargo, que las cuentas de 1669 son del obraje de Paucartambo y las de 1674 son de las estancias. Véase sección Socorros de Indios, años 1667-1677, 2 legs., Archivo Arzobispal de Lima (en adelante AAL).
} 
suficientes para garantizar el funcionamiento de las actividades privadas ubicadas en el entorno (o incluso dentro) de las comunidades y, por esto, se introducen mecanismos también compulsivos pero basados en un control individual (deudas).

Así, en la década de 1667 a 1677, se empieza a aplicar una nueva tarifa salarial elevando 50 \% el pago nominal a la vez que se duplica el monto del tributo que los indígenas debían redimir en trabajo; se impone la tarea fija, elevada y obligatoria en el obraje, y se incrementa la tarea en el pastoreo al multiplicar hasta por seis la cantidad de manadas y hasta por diez la cantidad de cabezas de ganado que debía cuidar cada pastor, sea mitayo o mingado (es decir, libre o asalariado).

Por otro lado, es posible que en la década se haya consolidado (o al menos afirmado) la sustitución de la mita minera en Huancavelica por la mita de plata en Bombón, así como el sistema de reparto de mercaderías entre los trabajadores de este complejo productivo y el cobro que hace por servicios eclesiásticos gracias a la labor de Andrés López Grayño. El empresario enfrenta la disminución drástica de la población indígena tratando de captar a los indios originarios y, sobre todo, a las indias y a los llamados indios forasteros a través de un endeudamiento que relativiza la eficacia de los mecanismos toledanos. Una importante parte de la población indígena está al borde de la yanaconización por quedar en desamparo respecto a las instituciones tradicionales andinas.

El andamiaje económico, social, político, cultural y religioso del régimen colonial descansó en el ordenamiento en pueblos del grueso de la población indígena realizado por el virrey Francisco de Toledo cuando la colonia pasaba de un modelo extractivo tributario-encomendero, a otro modelo productivo basado en la minería, las haciendas y los obrajes rurales y urbanos en la segunda mitad del siglo xvi. La reducción a pueblos debía garantizar el cobro de los tributos en dinero, el envío de indígenas a los trabajos rotativos pero obligatorios (mitas) en minas, haciendas, obrajes y ciudades, el control social y la cristianización. A cambio de estas prestaciones, la población indígena mantuvo recursos (tierras) en un nuevo pacto colonial que incluía el gobierno por sus propios curacas, aunque siempre supervisados por corregidores y sacerdotes doctrineros.

Décadas después de creadas las reducciones, los pueblos de indios habían cambiado de manera tan significativa que la historiografía los presenta como la confirmación del fracaso de las reducciones toledanas. Es probable que la crítica sea a los historiadores que entendieron el proyecto toledano como una experiencia perfecta e inalterable con base en la normatividad formal obviando el simple hecho de que un tema de tanta importancia para el funcionamiento del régimen colonial no podía permanecer intacto a lo largo del tiempo con tantos sectores sociales interesados en su adaptación según sus conveniencias. El ideal de comunidad perfecta y justa tuvo poca aceptación una vez que los propietarios locales, los mineros y los sacerdotes doctrineros en combinación con los corregidores empiezan a disputarse las tierras y la mano de obra de los pueblos.

La tremenda caída demográfica 2 afecta las capacidades de la comunidad y las hace vulnerables en muchos sentidos. En particular, a los pueblos les es cada vez más difícil cubrir las cargas coloniales en la prestación laboral (mitas) y en el pago del tributo por ser obligaciones solidarias.

Además, se instalan españoles, mestizos, negros y castas que toman en alquiler tierras comunales, practican el comercio y artesanías, y esto facilita la apropiación ilegal de tierras, pastos y aguas pertenecientes al rey o a las comunidades indígenas que, posteriormente, se legalizaba gracias a las

\footnotetext{
${ }^{2}$ Noble D. Cook (2010, pp. 259-271 y 350) vincula directamente el despoblamiento de los corregimientos de la sierra central con el trabajo minero en Huancavelica, así como con enfermedades y la huida a otros corregimientos para ubicarse como yanaconas y forasteros. De los 2000 tributarios que en 1549 tenían los cinco pueblos principales de la encomienda Chinchaycocha (Los Reyes, Los Sóndores, Carhuamayo, Ninacaca y Ullucmayo), hacia 1630 quedaban poco más de 1500 , además de cifras similares de muchachos menores de 18 años de edad.
} 
llamadas composiciones de tierras iniciadas en 1591. Así, surgen haciendas agrícolas y estancias ganaderas con obrajes textiles que requerían de un flujo permanente de mano de obra. Pero las reducciones pierden pobladores que salen a asentarse en otros pueblos como indios forasteros, o se hacen yanaconas (siervos adscripticios individuales) en haciendas o mingados en obrajes, ciudades y centros mineros. Los pueblos terminan siendo esenciales para reclutar y reproducir la mano de obra para las actividades privadas gracias a la colaboración de los curacas, en un proceso que se consolida en la segunda mitad del siglo XviI, cuando la economía peruana depende cada vez menos de la producción de plata de Potosí. ${ }^{3}$

No obstante que los pueblos mantienen todavía recursos para afrontar el embate de factores externos ${ }_{4}^{4}$ nuevas medidas los obligan a modificar los términos de las relaciones con los forasteros en materia laboral. El aumento de los tributos y de los turnos de mita, la aparición de la llamada mita de plata y los primeros momentos de la práctica de los repartos mercantiles están entre las innovaciones (Burga y Manrique, 1990, pp. 30-32; Glave, 2009, vol. II, pp. 408-418, 435-441; Lazo y Tord, 2007, vol. II, pp. 155-156; Quiroz, 2010, III).

La nueva economía es muy dinámica al potenciar y diversificar recursos, pero no hay que exagerar sus niveles de mercantilización ni su grado de monetización tanto en el intercambio de bienes como en la retribución del trabajo. Estas dificultades hacen que productos básicos como sal, coca, maíz, trigo, harina, aceite, cecinas y carnes sean usados como parte de la remuneración típica de una economía preindustrial (Quiroz, 2016).

Uno de los cambios principales se refiere al nuevo papel de los curacas. Sin dejar de representar y proteger a su gente, los curacas asumen una intermediación activa en la explotación de los recursos y la fuerza de trabajo de los pueblos indígenas. Además de cobrar el tributo, organizar las mitas y controlar a la población, los curacas participan directamente en el contrato temporal de indígenas con los propietarios de los alrededores (mingados en haciendas, obrajes, minas, transporte, etc.), distribuyendo a los trabajadores y cobrando los montos del dinero producto de estos tratos (Macera, 2014, pp. 745-748).

En efecto, gracias a la organización interna de los pueblos, los propietarios pudieron reclutar y retener la mano de obra que requerían pues la colaboración de los curacas permite localizar, endeudar y obligar a los indígenas a acudir a las actividades económicas fuera de los pueblos. Es decir, se crea un nuevo orden que sirve de base para el funcionamiento del mundo rural andino por buena parte del periodo colonial.

El tema gira en torno al trabajo compulsivo de personas legalmente libres, lo que ha llamado la atención de especialistas en historia laboral. Se ha vuelto común considerar como trabajadores libres en el sentido moderno a quienes no eran ni esclavos ni mitayos e, inclusive, se llega a afirmar que constituían un grupo privilegiado por sus supuestos elevados salarios y su autonomía laboral ${ }^{5}$ Manuel Miño (1993, pp. 76-83) da cuenta de las dificultades de los empresarios obrajeros

\footnotetext{
${ }^{3}$ Sobre los cambios experimentados en las reducciones a través del tiempo, véase la abarcadora compilación de Saitō y Rosas (2017) donde destacan los estudios de Jeremy Mumford (2012) y de Luis Miguel Glave (2009) sobre la implantación de las reducciones y, entre los casos referentes a zonas serranas, el aporte de Marina Zuloaga sobre Huaylas y el de Nozomi Mizota sobre Huamanga por ser muy útiles para entender el fenómeno aquí estudiado.

${ }^{4}$ Los pueblos venden sus excedentes y guardan los beneficios en sus cofradías y en sus cajas de comunidad que serán saqueadas con frecuencia por las autoridades (incluyendo la corona) (Zuloaga, 2012, pp. 228-233).

${ }^{5}$ Sobre esta visión para los trabajadores mineros, véanse Brown (2000, pp. 172-174) para México, y Cole (1985) y Tandeter (1992) para Potosí; Salas (1998, vol. I, pp. 409, 467) para los obrajes humanguinos. Sobre el trabajo en las haciendas cusqueñas, véase Macera (2014, pp. 735-741), así como la compilación de Quiroz y Bonnett (2009) para la diversidad de regímenes laborales en Hispanoamérica colonial.
} 
en Hispanoamérica para conseguir mano de obra al subrayar la compulsión como el mecanismo principal de reclutamiento y retención de los trabajadores para talleres que eran rechazados por los indígenas y mestizos por su bien ganada fama de ser centros de trabajo muy duro con retribuciones miserables. Sin ánimo de ser exhaustivo en esta discusión, es necesario señalar que el indígena habitante de los pueblos en realidad no gozaba de entera libertad personal y que el trabajo libre distaba de serlo en sentido estricto 6

En efecto, el estudio establece el impacto del cobro de tributos, la sustitución de la mita, el reparto de mercaderías, las cargas eclesiásticas y los adelantos en dinero en el reclutamiento y sujeción de una mano de obra que, en realidad, se reproducía con sus propios medios y no gracias a una remuneración en dinero o especie por su trabajo. En este sentido, se cuestiona la plena vigencia de los salarios en efectivo y el reparto como una práctica exigida por los mismos trabajadores.

Parte de la argumentación del debate actual de la llamada "gran divergencia" entre países desarrollados y atrasados recurre a la historia para conocer el impacto del colonialismo en las instituciones modernas y el salario real como variable para medir las diferencias en los ingresos de la población. Para el caso hispanoamericano, destacan en este debate los aportes de Engerman y Sokoloff (2005), Allen, Murphy y Schneider (2012), Arroyo, Davies y Zanden (2012), y Dobado y García (2014). Dobado y García parten de la existencia efectiva en Hispanoamérica de mercados de tierras, trabajo y capital basados en la propiedad privada moderna y, por consiguiente, de la presencia de trabajadores libres remunerados con dinero en efectivo, que incluso incrementaban sus ingresos gracias a horas adicionales de trabajo, el kajcheo en las minas, la ayuda de miembros de su familia y el reparto de productos. Consideran además que el trabajo asalariado se va convirtiendo en dominante conforme desaparece el trabajo coercitivo en el siglo XviII e inicios del siglo XIx. Sin embargo, la importante información que manejan se refiere sólo a ciudades y centros mineros hispanoamericanos donde, de hecho, el dinero en efectivo circuló en mayor medida que en el ámbito rural. En el extremo opuesto, Dell (2010) sostiene que la mita colonial es parte de las causas del atraso económico actual de los distritos andinos que estuvieron afectos a ese régimen laboral en el pasado.

\section{LAS ESTANCIAS, EL OBRAJE Y LOS PUEBLOS}

Este estudio vincula las condiciones laborales de los trabajadores indígenas con sus pueblos en el ejemplo de los pastores de cuatro estancias ganaderas (San Francisco de Chichausiri, San Lorenzo de Atocsaico, Santa Cruz de Chontas, y Llacsahuanca) y de los operarios del obraje de la Limpia Concepción de Paucartambo ubicados en la meseta de Bombón (entre Pasco y Junín actuales) durante la década comprendida entre 1667 y 1677.7 Las cuatro estancias y el obraje formaban

\footnotetext{
${ }^{6}$ Sobre las características diferenciadas del trabajo servil, libre y esclavo, véanse Bush (1996) y Engerman (1999). Bush y Engerman admiten la posibilidad de una servidumbre consentida cuando no ata personalmente, sino que vincula al siervo y al señor mediante el uso de tierras o el endeudamiento, aunque sea por montos impagables. Esta apreciación es útil pues, en el tiempo estudiado, Bombón no presenta el tipo de siervo personal andino, adscrito a la tierra o al obraje (yanacona), pero sí el siervo endeudado a partir de tratos en parte al menos supervisados por los jefes étnicos (curacas).

${ }^{7}$ Los pueblos Paucartambo, Ullucmayo, Palcamayo, Acobamba y Cacas (hoy Cajas) no están en la meseta de Bombón sino hacia el oriente de esta, pasando la llamada Cordillera Central. Huancabamba es un pueblo muy lejano en los llanos de la Amazonía.
} 
un complejo económico altoandino dedicado a la crianza de ganado lanar y a la confección textil (paños o "ropa de la tierra"), mientras que los pueblos aledaños proporcionaban y reproducían la mano de obra subsidiando así a la empresa.

La meseta de Bombón es uno de los centros principales de producción de ganado ovino de los Andes y sus lanas iban a obrajes en una geografía muy amplia (desde Huánuco, Tarma y todo el valle del Mantaro hasta Cajatambo y la sierra de Lima)(Hurtado, 2006; León, 2002, pp. 159-160) (véase mapa 1).

Por otro lado, el centro minero de Huancavelica y la ciudad de Lima eran los mercados principales de las carnes, las cecinas y las prendas textiles. Si los tejidos producidos en Paucartambo tenían una gran competencia de parte de la producción de otros obrajes de Tarma, Jauja, Cajatambo, Huamanga y el Cusco, más bien la carne y las cecinas de Bombón tenían en la capital del virreinato un mercado muy amplio y seguro.

El tiempo de estudio marca el inicio del apogeo de la producción obrajera en los Andes centrales y, quizá, también de la producción ganadera y sus derivados para el mercado local en crecimiento. Los estudios acerca de la producción textil andina muestran que en 1660 se inicia un periodo de crecimiento de los obrajes, tanto en producción de telas, cantidades de telares y mano de obra, que abarca hasta aproximadamente la década de 1770 (Escandell-Tur, 1997, p. 38; Salas, 1998, vol. I, pp. 91-108). El cierre del comercio de textiles desde Nueva España a los Andes, la menor disponibilidad de dinero para adquirir textiles europeos por las dificultades en la minería andina de plata y mercurio, el fortalecimiento del mercado interno gracias al crecimiento de ciudades, y la reorganización de los pueblos de indios como fuentes de mano de obra son parte de las condiciones en las que se origina este auge de la producción obrajera.

Sin embargo, a pesar de sus dimensiones similares a las de los más grandes centros textiles coloniales, el obraje de Paucartambo ha estado hasta ahora fuera de las discusiones en torno al papel de la producción obrajera en la economía colonial 8

Por la cantidad de indios tributarios y los montos del tributo, Chinchaycocha era considerada la cuarta encomienda más importante de la audiencia de Lima en el siglo xvi. Hasta mediados del siglo XviI, Chinchaycocha estuvo en manos de los condes de Las Lagunas, descendientes del poderoso conquistador-encomendero Juan Tello de Sotomayor, cuya fortuna se amplió al comercio, minas de plata (Yauricocha o Cerro de Pasco), estancias ganaderas y el obraje de Paucartambo, a pesar de las prohibiciones vigentes al respecto. La estancia Llacsahuanca fue legalizada en el primer proceso de composición de tierras a fines del siglo XVI (Puente y Janssen, 1997).

En 1667-1677, el dueño de al menos una de las cuatro estancias era el sacerdote Pedro de Vega. El empresario o administrador de las estancias y el obraje en esta década era Andrés López Grayño (o Grayno), personaje con una extensa y compleja red de aviadores y habilitadores (financistas) que incluía a párrocos (el vicario Nicolás Martínez Pardo, fray Alonso del Río, fray Alonso Valdivia) y agentes (Lope de la Vega, Carlos Chanca Huamán, Juan de Ortega, Juan de Narbasta, Ignacio Pando, Gabriel Cabello y el sargento Pedro Suárez Guerra). Sus principales proveedores eran comerciantes de Huancavelica y Lima.

\footnotetext{
${ }^{8}$ Es probable que esta omisión se origine en el error que cometiera Silva Santisteban (1964, p. 152), al confundir el pueblo de Paucartambo (Bombón) con la provincia de Paucartambo en el Cusco. Este error impidió que se buscara información sobre el obraje que nos ocupa aquí para incluirlo entre los centros textiles del valle medio del río Mantaro. Inclusive, la carátula del libro de 1673 del corpus documental usado para este artículo tiene una inscripción moderna hecha a crayón, señalando que se trata del Paucartambo de Cajamarca (en la sierra norte), y en otro documento de 1677 se repite el error, anotando en la carátula, también a crayón, que corresponde al Paucartambo cusqueño.
} 


\section{MAPA 1. BOMBÓN O CHINCHAYCOCHA}

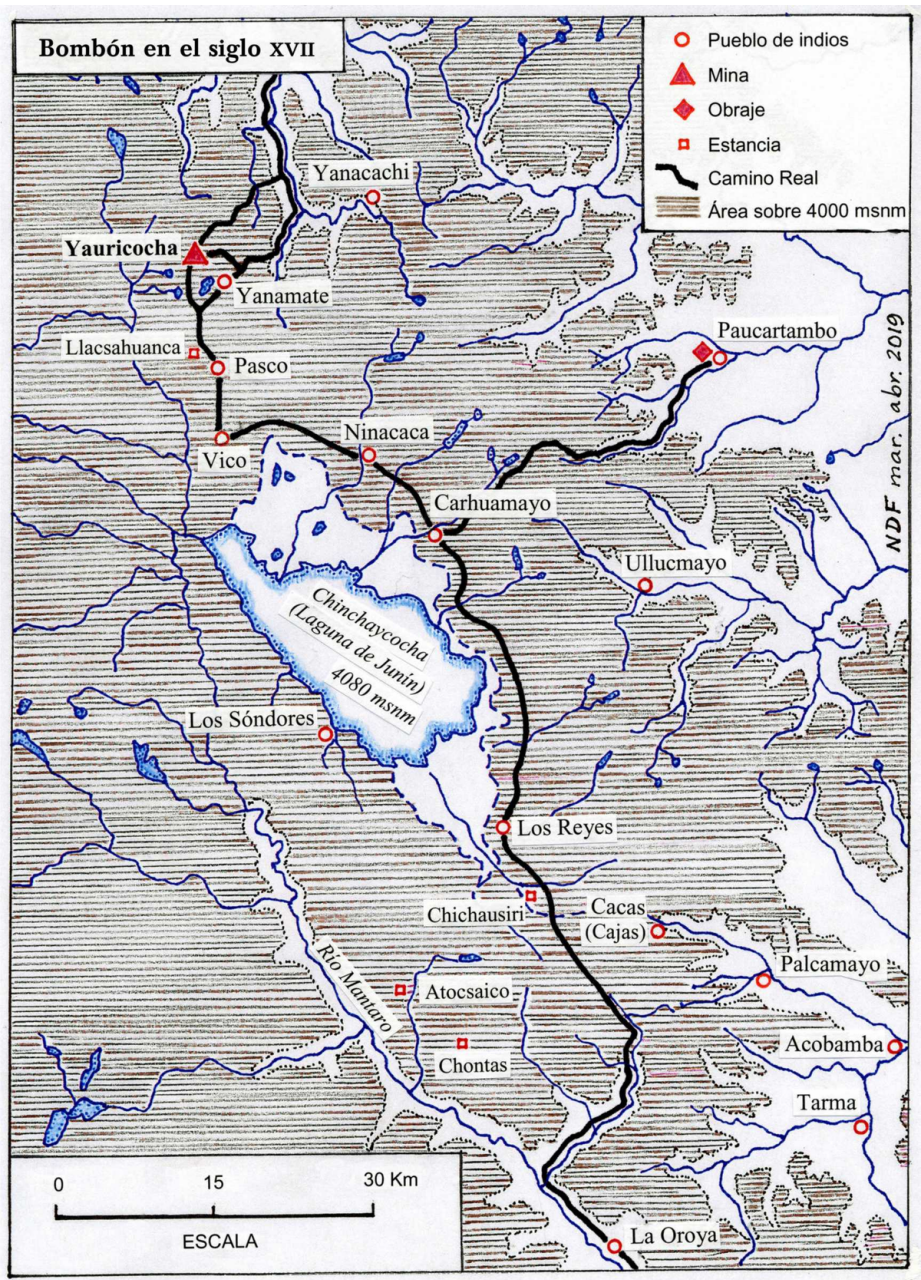

Fuente: elaborado por Nicanor Domínguez Faura (marzo-abril, 2019).

El complejo ganadero y textil estudiado se compone de quince pueblos de los alrededores de la laguna de Junín y compite con otras haciendas y obrajes de la zona por la ahora escasa mano de obra de los pueblos. De hecho, las reducciones seguirán siendo importantes, aunque ya no serán suficientes para garantizar el éxito de las empresas.

Los pueblos asumen el costo de reproducción de la mano de obra requerida por la empresa pecuaria y textil. Es decir, los pobladores se ven en la necesidad de alimentarse y vestirse recurriendo a sus propios medios, reemplazarse unos a otros, cubrir más turnos de mita de los que debían, y hasta ayudarse entre familiares para satisfacer las exigencias de los empresarios que remuneraban el trabajo con salarios insuficientes y, además, pagados de manera irregular.

Casi la totalidad de los pastores y operarios del obraje reclutados en pueblos residía en siete de los quince pueblos: Los Sóndores (hoy Ondores), Ullucmayo (hoy Ulcumayo), Carhuamayo, Paucartambo, Pasco y, en particular, Ninacaca y Los Reyes (hoy Junín). En efecto, la documen- 
tación muestra que el empresario del conjunto ganadero y textil tenía las redes establecidas principalmente con los curacas de los siete pueblos señalados y sus parcialidades como los principales abastecedores de trabajadores mitayos y alquilados (mingados). Estos pueblos también aparecen con mucha frecuencia en la documentación en las fiestas religiosas, situaciones propicias para el endeudamiento de los trabajadores potenciales y efectivos. Esto es central para este estudio pues debió ser fundamental la negociación entre los empresarios y los curacas, curas y corregidores para obtener la mano de obra necesaria. Al parecer, el obraje y las estancias habían logrado una suerte de cuotas de indígenas por parcialidad y pueblo, y es probable que fuesen los curacas quienes cobraban de manera directa el producto del trabajo de los indígenas que ellos mismos enviaban a los empresarios para cubrir las obligaciones colectivas de la comunidad para con el Estado colonial y la Iglesia.

\section{LOS TRABAJADORES}

El cuerpo documental utilizado tiene información detallada de 596 trabajadores con cuentas especiales en los libros mayores, o 652 trabajadores si consideramos también a los 56 que tienen cuentas sólo en otros libros parciales. De estos otros 56 (incluidas diez mujeres), la mayor parte (37 o $66 \%$ ) fue reclutada fuera de los pueblos habituales del complejo productivo. Hay, además, 21 personas (cinco mujeres) que no tienen cuentas propias a pesar de ser mencionados como trabajadores en diferentes momentos de la década, lo que hace pensar que tenían tratos diferentes con los empresarios.

Cabe decir que los trabajadores son indígenas 9 pero hay que aclarar que entre ellos figuran un negro y un mulato esclavos, una zamba libre (Isabel Sebastiana) y un mulato libre: Lorenzo de la Torre, quien en 1671 aparece como zambo, en 1677 es quipo de la estancia y estaba casado con la india María Jerónima Guacra. 10

Se puede sospechar de la presencia de mestizos, aunque los nombres y apellidos españoles no implican por sí solos el mestizaje: 106 trabajadores tienen nombres españoles, pero puesto que 18 de ellos cumplieron en algún momento su obligación de mita, es difícil que estos hayan sido mestizos. Otros 89, en cambio, no tuvieron obligación de mitas, y de la mayoría (70), se desconoce el pueblo de su residencia 11

\footnotetext{
${ }^{9}$ Los apellidos más frecuentes son nativos: 43 Huamán, 33 Poma, 27 Chagua, 25 Capcha, 22 Julca, 18 Quispe y Cóndor, quince Malqui, Huayna, Carhua y Guaraca, trece Vilca, doce Ricra, once Páucar, diez Pariasca, ocho Ricapa, Llacsa, Yauri y Palpa, siete Guaranga y Ticsi, seis Rupay, Huanca y Guayanay, cinco Choque, Luicho, Chilpe y Mayguay (todas mujeres), cuatro Llacuas, Yacolca, Guaychao, Chuquia, Taquiri, Callupe y Lleque, tres Michuy y Chauca, y dos Machaguay; así como diversas combinaciones de estos y otros apellidos andinos. Socorros de Indios, años 1667-1677, 2 legs., AAL.

${ }^{10}$ A diferencia de ciudades mexicanas (México, Querétaro y Puebla), en el Perú no se usaron esclavos africanos en cantidades importantes en las estancias ganaderas y obrajes textiles serranos, tal vez porque se encontró la forma para conseguir trabajadores en los pueblos andinos. Sobre la problemática esclava en los obrajes novohispanos, véase Proctor (2003).

${ }^{11}$ Sobre la complejidad del fenómeno del mestizaje colonial, véase Ares y Stella (2000). Por ejemplo, es difícil identificar en la documentación como indios a Diego Ramírez Bravo, Domingo de Araya (ayudante de quipo), Francisco Solano de Ochoa, Cristóbal Arias (hermano de Domingo Huamán Chaca y padre de Juan Arias), Juan Pérez Montero, o a los hijos del indígena Pedro Huamán Ricra (a quien llaman también Pedro Viera, del pueblo Ullucmayo): Juan de Castañeda, Francisco Mendoza y Graciana Ramos. Así como a los Riquelme: Cristóbal de la Cruz, Pablo, Fran-
} 
Este tema conduce a otro de no menor importancia para entender los regímenes laborales en una sociedad altoandina como la de Bombón en ese tiempo: la red de vínculos de parentesco real y espiritual que subyace a las relaciones laborales, tanto entre los empresarios y los trabajadores como entre estos últimos. Sin embargo, la información acerca del vínculo de parentesco figura en los documentos de manera ocasional y, en particular, cuando se trata de adjudicar la deuda pendiente de un trabajador fallecido o fugitivo a un familiar (padre, hijo, hija, hermano, hermana, primo, esposa, viuda, nieto, yerno o suegro). La realidad de los lazos familiares debió ser mucho más compleja y extendida si se tiene en cuenta la repetición de apellidos entre los trabajadores y la coincidencia de pueblos de origen y residencia. Un ejemplo de ello es el caso de Pedro Hilario Viquichi pues sí se especifica que es padre de Francisco Pascual López Viquichi, pero no se dice nada de Cristóbal López Viquichi, residente en el mismo pueblo de Ninacaca. En realidad, hermanos, padres e hijos no llevan siempre los mismos apellidos, lo que dificulta conocer mejor los vínculos de parentesco entre los trabajadores.

De las 21 parejas casadas de trabajadores con cuenta propia, cabe mencionar la de Ignacio Páucar y Luisa Cuscuy. Luisa, al enviudar en 1669, entra a trabajar por cuenta propia para cubrir las deudas de su difunto marido.

\section{TRABAJADORES Y PUEBLOS}

La importancia especial de los pueblos y ayllus (parcialidades) se aprecia en su papel como lugar de reserva de mano de obra para los negocios controlados por los grandes propietarios privados. La mitad de los trabajadores proviene de los pueblos y, en particular, de siete pueblos con sus parcialidades o ayllus que concentran el grueso de los trabajadores reclutados. Inclusive, dentro de los pueblos algunos ayllus tienen más reclutas que otros: llacsamaray (nueve trabajadores), chivian colca (nueve) y pomatoma (siete) de Carhuamayo; yacolca (diez), callao atunruna (diez), rocan y quiparacra (nueve cada uno) y yanayaco (ocho) de Ninacaca; y callao guara (18), tambos y julca (17 cada uno), chaupipacha (trece), collana (diez), curacapacha (nueve) y mariaca (ocho) de Los Reyes. Es posible que hayan sido los curacas de estos ayllus los que mantuvieran relaciones más favorables con los reclutadores de la empresa 12 Así, los 289 mitayos y alquilados reclutados en la década (1667-1677) en los quince pueblos corresponden a tan sólo $48 \%$ del total de mano de obra del complejo económico (véase cuadro 1 ).

cisco, Lorenzo, Domingo, Juan, Pedro, Isabel Agustina y María Ramos, o a los Leyva: Luis, Juan José, Lorenzo Asto, María Josefa y Pascuala Mayguay, todos ellos sin especificación del pueblo de procedencia. Socorros de Indios, años 1667-1677, 2 legs., AAL.

${ }^{12}$ Existen cuatro casos cuyo registro de pueblos o parcialidades de donde son originarios los indígenas genera confusión. Pablo Capcha Comendero figura en 1667 como del ayllu mariaca del pueblo Los Sóndores, pero en 1673 es del ayllu mariaca del pueblo Los Reyes y en 1677 del ayllu julca del mismo pueblo. Juan Malqui Chagua figura como originario del pueblo Los Reyes, pero en 1674 como de las parcialidades yanacocha e ychocan en Los Sóndores. Gaspar Melchor es considerado de Ullucmayo en 1667 pero en 1671 y 1674 de Carhuamayo (ayllu llacsamaray). Por último, Pablo Huamán Yauri aparece como originario de Los Reyes (ayllu yauri) en 1667, de Ullucmayo en 1669 y de Paucartambo en 1673. Son pocos los casos como para aventurar una explicación acerca de si se trata de errores rectificados o la manifestación de disputas entre los curacas de los pueblos y parcialidades por su gente que podía gozar de una relativa movilidad entre los pueblos. Socorros de Indios, años 1667-1677, 2 legs., AAL 


\section{CUADRO 1. TRABAJADORES DE LAS ESTANCIAS Y EL OBRAJE. CONDICIONES DE TRABAJO POR PUEBLOS}

\begin{tabular}{lrcccccc}
\hline & & & & & \multicolumn{3}{c}{ Alquilados- } \\
Pueblos & Total & Varones & Mujeres & Alquilados & Mitayos & mitayos & Presos \\
\hline Los Reyes & 93 & 88 & 5 & 54 & 5 & 33 & 1 \\
Ninacaca & 73 & 68 & 5 & 33 & 12 & 27 & 1 \\
Carhuamayo & 30 & 27 & 3 & 5 & 5 & 19 & 1 \\
Ullucmayo & 21 & 18 & 3 & 5 & 5 & 9 & 2 \\
Paucartambo & 19 & 19 & 0 & 13 & 2 & 4 & 0 \\
Los Sóndores & 18 & 18 & 0 & 9 & 2 & 7 & 0 \\
Pasco & 15 & 15 & 0 & 15 & 0 & 0 & 0 \\
Palcamayo & 5 & 5 & 0 & 0 & 4 & 0 & 1 \\
Vico & 4 & 4 & 0 & 4 & 0 & 0 & 0 \\
Cacas & 3 & 3 & 0 & 3 & 0 & 0 & 0 \\
Yanacachi & 2 & 2 & 0 & 2 & 0 & 0 & 0 \\
Acobamba & 2 & 2 & 0 & 1 & 1 & 0 & 0 \\
Chinchan & 2 & 2 & 0 & 1 & 0 & 1 & 0 \\
Yanamate & 1 & 1 & 0 & 1 & 0 & 0 & 0 \\
Huancabamba & 1 & 1 & 0 & 1 & 0 & 0 & 0 \\
Subtotal & 289 & 273 & 16 & 147 & 36 & 100 & 6 \\
Sin precisar & & & & & & & \\
Varones & - & 172 & - & 159 & 1 & 6 & 6 \\
Mujeres & - & - & 135 & 135 & 0 & 0 & 0 \\
Subtotal & 307 & 172 & 135 & 294 & 1 & 6 & 6 \\
Totales & 596 & 445 & 151 & 441 & 37 & 106 & 12 \\
\hline
\end{tabular}

Fuente: elaboración propia con base en Socorros de Indios, años 1667-1677, 2 legajos, AAL.

Pero, la documentación no consigna el pueblo de origen o residencia de $52 \%$ de los trabajadores (307). Algunos de estos trabajadores pudieron ser indios forasteros provenientes de otros pueblos ${ }^{13}$ En todo caso, eran reclutados sin tener en cuenta la obligación del pago del tributo o de la mita estanciera u obrajera y, por consiguiente, a la mitad de los trabajadores hubo que reclutarlos a través de otros mecanismos. Sin duda, este dato es importante pues muestra que los pueblos mantenían su papel central en el ordenamiento de la mano de obra, pero ya no eran indispensables para cubrir las necesidades de trabajadores para las empresas que los propietarios privados tenían en la zona.

\footnotetext{
${ }^{13}$ No he atribuido residencia en un pueblo determinado a los 60 trabajadores ( 27 varones y 33 mujeres) con expreso lazo de parentesco con trabajadores de ese pueblo, pues el reclutamiento en estos casos se produjo al margen de los pueblos. De ellos, seis varones tenían a sus hijos en pueblos, ocho tenían a sus cónyuges (una mujer), tres a sus hermanos (dos mujeres), 38 a sus padres (quince varones y 23 mujeres), tres a sus tutores (una mujer), así como uno a su abuelo y otro a su primo.
} 
Es claro que prevalecen los trabajadores alquilados, es decir los formalmente voluntarios y asalariados (mingados). Son 441 los que trabajan en esta condición y constituyen las tres cuartas partes del total $(74 \%)$. Los que trabajan en la condición de mitayos son 37 (6\%, incluyendo a cuatro mujeres), mientras que los que figuran en un mismo libro de cuentas unas veces como alquilados y otras como mitayos son $106(18 \%)$. Además, doce trabajadores son presos o llevados a trabajar por alguna deuda específica, incluida una mujer ( $2 \%)$.

Las cifras mostradas por años evidencian la falta de datos en todos los casos. Y aunque se pueden tomar las cuentas de 1671 como una muestra realista de la fuerza laboral del complejo ganadero y textil, de todas maneras, llama la atención que ese año presente una cantidad muy limitada de mitayos: 32 contra los 55 de 1667 y los 70 de 1669. Además de falta de información, al parecer estamos ante una mayor evasión 14 (véase cuadro 2).

Del total de 596 trabajadores registrados en los momentos señalados, 456 eran varones $(75 \%)$ y 151 mujeres (25\%). De todas maneras, la presencia significativa de mujeres es importante porque con ellas no existía el mecanismo de coerción relacionado con el pago del tributo, con la mita en las estancias ni con el obraje y, menos, con la conmutación de la mita minera en Huancavelica. Con ellas se debió aplicar otros mecanismos, aunque en cuatro casos sí se usó el de la mita y el tributo (quizá en sustitución de familiares varones). Sobre todo, es interesante advertir que 135 mujeres $(83 \%)$ fueron reclutadas sin considerar el pueblo de pertenencia y, en general, es muy bajo el nivel de endeudamiento que tienen. Karen B. Graubart (2007, pp. 31-38) encuentra que el tejido se convierte en una actividad femenina en los Andes coloniales, pero esto incluye el trabajo en obrajes, obrajillos (chorrillos) y a domicilio.

El obraje de Paucartambo no era pequeño, incluso en comparación con los mayores obrajes de dos de las zonas obrajeras más importantes del Perú colonial: Cacamarca, Chinchero y Pomacocha en Huamanga 15 y Huaro y Pichuichuro, en el Cusco ${ }^{16}$ (véase cuadro 3 .

Si los montos globales de trabajadores en las estancias y el obraje son un índice del grado de necesidad de uso de la mano de obra por parte de los empresarios, la frecuencia con que aparecen los trabajadores en los libros refleja tanto la necesidad de los propios trabajadores por emplearse (o la urgencia de los pueblos por enviar a trabajar a parte de sus miembros para cubrir obligaciones colectivas) como la necesidad y la posibilidad de los empleadores para contar con los mismos trabajadores para las labores. Aun teniendo en cuenta las omisiones en la documentación, se tiene que 278 trabajadores (47\%) figuran una sola vez en los 1151 registros de trabajo, mientras que 146 lo hacen dos veces (24\%), 108 lo hacen tres veces (18\%), 63 cuatro veces (10\%), y sólo uno cubre los cinco registros (véase cuadro 4 ).

\footnotetext{
${ }^{14}$ El virrey Toledo asignó 60 mitayos al obraje de Paucartambo (la mitad de ellos muchachos). En 1601 el virrey Luis de Velasco añadió 130 muchachos mitayos y en 1622 el príncipe de Esquilache otros 120 mitayos. No queda claro si estas cifras se suman o son ratificaciones, pero según Puente y Janssen (1997, pp. 116, 122-123), ante una queja de los curacas a mediados del siglo XVII se establece que la mita debe regirse según la séptima parte de los tributarios y ya no más por la sexta parte. No se conoce la cantidad de indios tributarios en este tiempo, pero la séptima parte no dio más de 70 mitayos en 1669, el mejor de los años del periodo de estudio en cuanto al obraje. Es decir, esos pueblos de Chinchaycocha debieron tener entre 500 y 600 indios tributarios, una tercera parte de los 1500 de 40 años antes que estimara Cook (2010, p. 350).

${ }^{15}$ Para 1694, Cacamarca tenía 147 operarios, 295 en 1730, 360 en 1732 y entre 220 y 240 operarios en 1770 (Salas, 1998, vol. I, pp. 391, 441 y 484).

${ }^{16}$ Huaro, el más importante obraje del Cusco en la segunda mitad del siglo XviI, cuenta con 267 operarios y 63 operarias en 1699. El obraje jesuita Pichuichuro tiene 205 operarios en 1742, 270 en 1766, 283 en 1772 , 308 en 1791 y 157 operarios en 1803 (Escandell-Tur, 1997, pp. 400-401).
} 
CUADRO 2. CONDICIONES DE LOS TRABAJADORES POR AÑOS, 1667-1677

\begin{tabular}{lccccc}
\hline Años & Alquilados & Mitayos & $\begin{array}{c}\text { Alquilados- } \\
\text { mitayos }\end{array}$ & Presos & Totales \\
\hline 1667 & 159 & 50 & 5 & 0 & 214 \\
1669 & 221 & 69 & 1 & 0 & 291 \\
1671 & 295 & 18 & 14 & 12 & 339 \\
1674 & 61 & 9 & 7 & 0 & 77 \\
1677 & 219 & 2 & 9 & 0 & 230 \\
\hline
\end{tabular}

Fuente: elaboración propia con base en Socorros de Indios, años 1667-1677, 2 legajos, AAL.

CUADRO 3. TRABAJADORES POR CENTRO DE TRABAJO, 1667-1677

\begin{tabular}{lrrrrc}
\hline Centro de trabajo & 1667 & 1669 & 1671 & 1674 & 1677 \\
\hline Estancias & 73 & 1 & 57 & 77 & s. d. \\
Obraje & 139 & 290 & 274 & s.d. & 230 \\
Estancias y obraje & 2 & s. d. & 8 & s.d. & s. d. \\
Totales & 214 & 291 & 339 & 77 & 230 \\
\hline
\end{tabular}

Fuente: elaboración propia con base en Socorros de Indios, años 1667-1677, 2 legajos, AAL.

CUADRO 4. FRECUENCIA DE REGISTROS EN LOS LIBROS, 1667-1777

\begin{tabular}{lcccccc}
\hline Registro & Totales & Porcentaje & Hombres & Porcentaje & Mujeres & Porcentaje \\
\hline 1 & 278 & 47 & 201 & 45 & 77 & 51 \\
2 & 146 & 24 & 97 & 22 & 49 & 32 \\
3 & 108 & 18 & 83 & 18 & 25 & 17 \\
4 & 63 & 11 & 63 & 14 & 0 & 0 \\
5 & 1 & 0 & 1 & 0 & 0 & 0 \\
Total & 596 & & 445 & & 151 & \\
\hline
\end{tabular}

Fuente: elaboración propia con base en Socorros de Indios, años 1667-1677, 2 legajos, AAL.

Las mujeres constituían la cuarta parte de quienes se registraron una sola vez (77 de 278 casos), la tercera parte de los que se registraron dos veces ( 49 de 146 casos), y algo menos de la cuarta parte de quienes tuvieron tres registros (25 de 108 casos). Así, la mitad de las 151 mujeres se registra una sola vez, la tercera parte dos veces y sólo la sexta parte aparece en tres registros diferentes (véase cuadro 5).

En realidad, se debe restar de estas cifras a aquellos trabajadores que no figuran en los cuatro momentos señalados pero que arrastran deudas de años pasados, lo que permite inferir que ya habían trabajado en años anteriores. Así, al menos 27 de los 75 trabajadores y trabajadoras de las estancias en 1667 llegan con deudas anteriores y cuatro con acreencias anteriores. Es decir, sólo 48 son nuevos. 
CUADRO 5. Frecuencia de registros por pueblos, 1667-1677

\begin{tabular}{|c|c|c|c|c|c|c|}
\hline Pueblos & 1 & 2 & 3 & 4 & 5 & Totales \\
\hline Reyes & 38 & 17 & 20 & 18 & 0 & 93 \\
\hline Ninacaca & 28 & 27 & 13 & 4 & 1 & 73 \\
\hline Carhuamayo & 8 & 7 & 8 & 7 & 0 & 30 \\
\hline Ullucmayo & 10 & 5 & 4 & 2 & 0 & 21 \\
\hline Paucartambo & 3 & 1 & 5 & 10 & 0 & 19 \\
\hline Los Sóndores & 8 & 1 & 5 & 4 & 0 & 18 \\
\hline Pasco & 7 & 8 & 0 & 0 & 0 & 15 \\
\hline Palcamayo & 5 & 0 & 0 & 0 & 0 & 5 \\
\hline Cacas & 2 & 2 & 0 & 0 & 0 & 4 \\
\hline Vico & 1 & 2 & 0 & 0 & 0 & 3 \\
\hline Yanacachi & 2 & 0 & 0 & 0 & 0 & 2 \\
\hline Acobamba & 2 & 0 & 0 & 0 & 0 & 2 \\
\hline Chinchan & 2 & 0 & 0 & 0 & 0 & 2 \\
\hline Yanamate & 0 & 1 & 0 & 0 & 0 & 1 \\
\hline Huancabamba & 1 & 0 & 0 & 0 & 0 & 1 \\
\hline No especifica varones & 95 & 30 & 29 & 18 & 0 & 172 \\
\hline No especifica mujeres & 66 & 45 & 24 & 0 & 0 & 135 \\
\hline Totales & 278 & 146 & 108 & 63 & 1 & 596 \\
\hline
\end{tabular}

Fuente: elaboración propia con base en Socorros de Indios, años 1667-1677, 2 legajos, AAL.

El caso del obraje es más ilustrativo pues sólo catorce de los 25 trabajadores que aparecen por primera vez en 1667 eran nuevos en el trabajo; lo mismo que 24 de los 61 en 1669; 34 de los 54 en 1671, y 20 de los 87 en 1677. Entonces, de los 480 trabajadores en el obraje en la década estudiada, sólo 92 tienen una única experiencia laboral y no 227 como se infiere de la documentación disponible. Sólo en tres casos se deja constancia de que se abre la cuenta por ser nuevos, tanto en las estancias como en el obraje (todos son de 1667: Pedro Camacho de Ochoa, Ignacio Ticsi Huamán y Pedro Julca).

Entonces, se debe relativizar el carácter eventual del trabajo. Los trabajadores eran más permanentes en las unidades productivas rurales de lo que las fuentes dicen y, por consiguiente, se puede pensar que sí funcionaban los mecanismos de compulsión (mitas, tributos, endeudamiento, etc.) y de atracción (salarios) que aplicaban los empresarios gracias a sus tratos con los curacas, corregidores y curas ${ }^{17}$ sin embargo, esos mecanismos no fueron suficientes.

\footnotetext{
${ }^{17}$ Aunque sin proporcionar cifras concretas, Escandell-Tur (1997, p. 371) encuentra que la comunidad indígena (pueblos) era la principal proveedora de la fuerza de trabajo de los obrajes cusqueños. Al parecer, los obrajeros huamanguinos tuvieron mejor suerte pues, de acuerdo con Salas (1998, vol. I, pp. 247, 372, 385-390 y 441), desde mediados del siglo XVII lograron yanaconizar a la fuerza laboral y, por consiguiente, tenerla de manera permanente en los obrajes.
} 


\section{RECLUTAMIENTO Y RETENCIÓN}

Las cifras proporcionadas sobre la frecuencia de asistencia de los trabajadores a las estancias y el obraje, muestran que los empresarios implementaron con éxito mecanismos económicos y extraeconómicos para atraer y asegurar la mano de obra necesaria para el funcionamiento de sus actividades. A continuación, se muestran los mecanismos usados para reclutar y retener a los trabajadores.

En el caso del tributo y la mita, los pueblos se desempeñaron como centros de reclutamiento pues los indígenas eran afectos al pago de tributos y al cumplimiento de las mitas en las estancias, obrajes, al igual que a la mita en la mina de azogue de Huancavelica.

La mita a favor de las minas, estancias y obrajes revela cifras pequeñas (y en franca disminución a través del tiempo) que hacen pensar en qué tanta importancia tenía en el complejo mundo laboral hispanoamericano colonial. Sin embargo, debemos tener en cuenta que, con cantidades pequeñas, como pudo haber sido, la mita fue un criterio ordenador del trabajo, pues los turnos de trabajo compulsivo garantizaban la afluencia de una cantidad básica de trabajadores a partir de la que se debía buscar la mano de obra restante o complementaria.

Hablar de mitas y tributos es referirse a montos de dinero bastante altos para la economía campesina indígena. En efecto, en el tiempo estudiado, el monto anual del tributo que debían pagar con su trabajo los indígenas de Bombón se incrementó de manera muy considerable. De 24 reales anuales en 1666 pasó a 32 reales en 1667-1669, a 40 reales en 1673 y a 48 reales en 1674-1677. Es decir, en una década los empresarios cotizaron más barato el trabajo para efectos de la paga del tributo al duplicar el monto de tres a seis pesos anuales.

Los 218 casos consignados en los libros de Socorros corresponden a aquellos indios que cancelaban el tributo con su trabajo en las estancias o el obraje; y representan $36 \%$ de los 596 indios registrados y $47 \%$ de todos los varones ${ }^{18}$ Gonzalo Flores paga en seis ocasiones el tributo con su trabajo por un monto global de 149 reales, pero 16 trabajadores figuran cinco veces con montos que varían entre 128 y 188 reales (véase cuadro6).

Las estancias ganaderas requerían menos trabajadores para funcionar y, debido a que la mita agrícola no era la prioridad del régimen colonial, estaba menos organizada que la minera y la de plaza (Glave, 2009, vol. II, p. 439) ${ }^{19}$ Así, los mitayos fueron una parte limitada de la fuerza laboral: $16 \%$ de 1151 registros de trabajo correspondía a trabajadores con turnos de la mita obrajera o ganadera. En ciertos años, sin embargo, la proporción aumenta de manera considerable (con $25.7 \%$ en 1667 y $24 \%$ en 1669 ), pero en otros cae a cifras muy poco significativas, tal como sucede en 1677, en que $4.7 \%$ de los trabajadores labora como mitayo. Más bien, la mita servía para llevar a trabajadores de los pueblos a las estancias y al obraje y, una vez ahí, retenerlos en el trabajo. Así, de 143 mitayos, al menos 35 corresponden a mitayos que se quedaron como alquilados en las estancias o en el obraje luego de cumplido su turno.

\footnotetext{
${ }^{18}$ En 1667 y $1671-1675$ se cuenta con datos para los dos semestres, en tanto que para los años 1668,1669 y 1677 la información corresponde a un solo semestre.

${ }^{19}$ Este procedimiento traía dificultades pues a veces faltaban indios para cubrir los cupos de mita en el obraje. Así lo hacen notar los folios vacíos en los libros, pero también indicaciones como la que se hizo en el libro de 1669 en el sentido de que Cristóbal Atau Páucar estaba cumpliendo la mita obrajera "por fallas del ayllo de atunruna", pese a ser él del ayllu ychocamacocha. O que el agente del empresario López Grayño retuvo 103 reales que "alcanzó” Antón Pascual Cristiano y que debía su padre Juan Bautista Cristiano por los indios ausentes de su partida. Véase Documento sin título, 1669, Libro de pagos, Obraje de Paucartambo, 1669. Socorros de indios, leg. 1 c. (1), fs. 39 y $75 \mathrm{v}$, AAL.
} 


\section{CUADRO 6. SUMAS PAGADAS POR EL CONJUNTO DE INDIOS TRIBUTARIOS DEL COMPLEJO GANADERO-TEXTIL EN REEMPLAZO DEL TRIBUTO (EN REALES), 1667-1677}

\begin{tabular}{rrrrrrrrr}
\hline 1667 & 1668 & 1669 & 1671 & 1672 & 1673 & 1674 & 1675 & 1677 \\
\hline 986 & 392 & 1078 & 2384 & 586 & 3552 & 1292 & 1084 & 1536 \\
\hline
\end{tabular}

Fuente: elaboración propia con base en Socorros de Indios, años 1667-1677, 2 legajos, AAL.

La mayoría de los mitayos proviene de pueblos determinados: Los Sóndores, Ullucmayo, Carhuamayo, Paucartambo, Ninacaca y Los Reyes: 31 de 37 mitayos, y 101 de 106 alquilados y mitayos. De todos ellos, unos cuantos trabajaron en su condición de mitayos con más de un registro en la década que cubre la documentación: Pedro Capcha Cemita y Juan Capcha Cemita del pueblo Los Sóndores; Pascual Guayanay, Pablo Blancas, Francisco Carlos y Pedro Campuzano (Ninacaca); Agustín Taquiri Macua y Juan Ramos Sicasica (Los Reyes), y Sebastián Carhua Pachin (Paucartambo). Además de los cuatro mitayos reclutados en 1667-1668 en el pueblo de Palcamayo, Juan Baltasar Palcamayo trabajó forzado en 1671.

No parece haber sido común el reemplazo en los turnos de mita, pero es el caso de Jerónimo Cayas quien, luego de servir de mitayo un mes y medio en la estancia Chichausiri, concertó con Lucas Chantayco Capcha para que lo reemplazara en esta obligación por igual tiempo. Luego de servir por Cayas, Lucas Chantayco Capcha continuó sirviendo de mitayo por otro indio del mismo pueblo (Acobamba) por tres meses. A los mitayos sustitutos se les llamaba alquiles 20

Los indios de la zona eran también afectos a los turnos de la mita minera en Huancavelica 21 Los empresarios en Bombón, sin embargo, buscaban evitar que su mano de obra potencial se alejara a través de un procedimiento común ya en el siglo xvII: sustituir el viaje a Huancavelica por dinero o mita de plata ${ }^{22}$ No es que el trabajo en las estancias o en el obraje haya sido más llevadero, pero de seguro era preferible al traslado a la mina de Huancavelica con los conocidos riesgos para la salud y la vida, y las largas ausencias de sus pueblos, familia y tierras. ${ }^{23} \mathrm{Al}$ respecto,

\footnotetext{
${ }^{20}$ Libro de Socorros de los yndios pastores de las estancias de San Francisco de Chichausiri y Santa Cruz de Chontas que corre desde primero de julio deste año de mil y seiscientos y setenta y quatro, con advertencia que estan ajustadas las quentas de dichos pastores hasta fin de junio de dicho año de setenta y quatro y lo que alcanzaron se les pagó en sus propias manos. Y a los que quedaron a deber se les hizo cargo en este libro a cada uno por sí en su quenta y a los que han entrado nuevamente se les ban armando sus quentas para que con claridad se les hagan sus ajustes por los libros de estancias y este libro se compone de cuarenta y siete foxas numeradas desde numero primero asta numero cuarenta y siete para este año de 1674. Socorros de indios, leg. 2 c. (5), f. 25, AAL.

${ }^{21}$ Una información de 1630 señala que las quince estancias de Caujo y Bombón tenían asignados ese año 153 pastores mitayos para la guarda de 400000 cabezas de ganado menor cuando el régimen colonial deriva a 95 de ellos a la mita de Huancavelica. Véase Concejo Provincial de Lima (1935, xxı, pp. 286-287).

${ }^{22}$ La mita de plata está ligada a la decadencia de la producción de Potosí, Huancavelica y otras minas. Entre otros mecanismos a los que recurren para mantener sus utilidades, los mineros aceptan dinero en lugar de trabajadores mitayos para contratar trabajadores mingados (nominalmente libres). Se estima que en la segunda mitad del siglo XVII cerca de la mitad de los trabajadores mitayos no acudía a las minas. Así, los pueblos de Bombón terminan sosteniendo una economía minera en Huancavelica. Véase Povea (2014, pp. 213-242).

${ }^{23} \mathrm{Si}$ la huida es una manifestación de disconformidad, Bombón no es un buen ejemplo. En realidad, existen 18 casos de trabajadores huidos entre 1667 y 1677. De ellos, once trabajadores huidos no aparecen más en los registros (tres de ellos figuran sin el pueblo de su residencia). Entre los fugitivos sin dejar rastro figuran dos padres con sus hijos, todos del pueblo Ullucmayo. Otros siete huyeron, pero aparecen posteriormente en los registros, incluido Pedro Julca
} 
una referencia a lo temible que era el trabajo en Bombón la hallamos en una declaración por el caso de idolatrías de 1677 en el pueblo de Maray (Cajatambo, al otro lado de la Cordillera Occidental). Los indígenas de Cajatambo debían mitar en las estancias y obrajes de Chinchaycocha, y antes de partir "lo mingavan [al acusado de hechicero] para tener buenos sucessos en las mitas que yban a hazer asi a Bombon como al obraxe"24

El mecanismo de la mita de plata era el siguiente. Los agentes de López Grayño acordaban en los pueblos, las estancias y el obraje con los gobernadores y piscapachacas de los pueblos y las parcialidades (ayllus) pagar los montos pactados con los mineros de Huancavelica para redimir a los indios de los turnos de la mita minera. Sin embargo, en lugar de dinero en efectivo enviaban productos de la zona (incluyendo textiles del obraje y cecinas de las estancias) a cargo de un comerciante para su venta en Huancavelica antes de entregar los montos acordados a los mineros 25 diferencia en los precios de los productos añade una ventaja adicional a favor de los empresarios.

Los 148 casos registrados de pago para no ir a Huancavelica involucran a la tercera parte de todos los varones. Exonerarse de ir a trabajar durante dos meses a Huancavelica costaba a los indígenas de la meseta de Bombón la exorbitante suma de 480 reales cada tres o cuatro años (es decir, lo que podían aspirar a recibir en un año de trabajo en una estancia u otras tantas tareas en el obraje). A este monto el empresario agregaba ocho reales (un peso) de su comisión para los gastos de la operación, con lo que incrementaba la ya abultada deuda que debía ser pagada en trabajo. Esta exoneración de ir a la mina, sin embargo, no eximió a al menos 20 indígenas de cumplir sus turnos de mita en las estancias o en el obraje en Bombón.

Con información entrecortada, se tiene que, en promedio, los trabajadores redimen en dinero 2.3 veces la mita de Huancavelica, pero 27 de ellos lo hacen tres veces en la década de 16661677, 16 lo hacen cuatro veces y tres lo hacen cinco veces. En cuanto a trabajadores individuales, los mayores montos de deuda por la exoneración los tiene Juan Alonso Huamán Chagua con 2296 reales, seguido de Cristóbal Arias con 2024 reales (aparte de 146 reales que debía por tributo pagado por el empresario) y Pedro Ayacsongo con 1936 reales (aparte de 146 reales por su tributo). La racionalidad económica de este reemplazo para el trabajador y la comunidad consistía en la posibilidad de utilizar el tiempo que no se empleaba en la mita (incluyendo el trayecto de ida y vuelta), en actividades regulares que generaran un provecho efectivo o simbólico mayor al entregado para la exoneración. Como ya se señaló, los curacas determinaban cuáles de los indígenas de sus pueblos debían acudir a las estancias o al obraje a trabajar más de un año en sustitución del trabajo efectivo de dos meses en la mina de Huancavelica, a pesar de que esto obligaba a los familiares de los comuneros a trabajar en su reemplazo.

Caqui (pueblo Ninacaca), trabajando como mitayo y alquilado en las estancias y el obraje. Al parecer, los curacas los encontraban y devolvían al trabajo. Alonso Palpas (pueblo Ullucmayo) había trabajado de pastor alquilado y mitayo en 1667, pero en 1674 huyó y su lugar en la estancia lo ocupó su esposa.

${ }^{24}$ Caussa criminal serca de la ydolatria en que coperaron algunos yndios del pueblo de Santiago de Maray repartimiento de Checras corregimiento de Chancay. Año de 1677. Hechicerías e Idolatrías, leg. 7, exp. 14, f. 35. AAL. Véase Agustín Bardales (2016).

${ }^{25}$ Memoria de las mitas que pagué por los indios del obraje que es la de noviembre y diciembre de 1674, por los chaupis que las recibió su gobernador y piscapachaca. Documento sin título 1673-1674. Socorros de indios, leg. 2 c. (3), AAL. 
Este procedimiento debió ser muy conveniente para los empresarios; a pesar de que debían realizar desembolsos muy considerables, los hacían por ser una vía al parecer muy segura para abaratar costos y reclutar y retener mano de obra en las estancias y el obraje 26

De esta manera, tributos, mitas y mita de plata eran mecanismos que dependían de la relación de los empresarios con las autoridades de los pueblos. Los representantes de los indios debían cuidar que el trato de no involucrar a más indios de los debidos y, en particular, que se respetaran las exoneraciones de sus indios a fin de poder contar con ellos en las obligaciones de sus propios pueblos. Los curacas llevaban una cuenta paralela con sus propios quipos (registradores) en quilcas o libretas especiales. Por ejemplo, en el ajuste de mayo y junio de 1674 se anotan ciertas condiciones que revelan el manejo de las mitas y el trabajo en Bombón. Al recibir 488 reales para que Pedro Quispe Huamán Ulluclla no fuese a Huancavelica, su gobernador certifica que le había dado dos meses de descanso en la mita y, de esa manera, el siguiente turno en Huancavelica u otra obligación similar en Bombón debería ser en el bimestre julio-agosto de 1675. Por su parte, Juan de Castañeda y Sebastián Malqui Soto “ajustaron la mita entera que tocó al ayllu collana de este pueblo de Paucartambo de dicho año que está referido de mayo y junio de 1674" 27

Resulta interesante una aclaración hecha en septiembre-octubre de 1674 para entender la intención del empresario y su confianza en que la mita de plata funcionaba. Al hablar de un mitayo, dice que paga por él 242 reales por un mes de mita aun cuando "este Pedro Julca Guaraca no vino en la memoria de Juan de Ortega y, por decirme don Carlos que avia venido al pueblo a sembrar su maca y su muger y dos hijos estaban en la estancia con la manada, los pagué". Es decir, el trabajador mitayo continúa con el trabajo en su chacra mientras sus familiares cumplen en la estancia con el trabajo que debía sustituir el que debía efectuarse en Huancavelica 28

Otros mecanismos no tienen a los pueblos como lugares de reclutamiento. El caso de los trabajadores conminados de manera directa (presos) no parece haber sido significativo pues sólo doce trabajadores aparecen como forzados y todos corresponden al obraje de Paucartambo en 1671. Incluso, tres presos figuran luego en condiciones aparentemente libres en el obraje.

Sólo para ilustrar esta modalidad de reclutamiento, veamos el caso de Juan Luis. El 9 de julio de 1671 el empresario López Grayño entregó 80 reales a Juan Luis en el pueblo de Acobamba "con calidad que a de venir a trabajar y no ha venido hasta ahora, dio por su fiador a su suegro [Rodrigo Julca del pueblo de Ullucmayo]”. Luego se consigna que llegó el 11 de agosto, llevado por el enganchador Gabriel Cabello, y que recibió otros 24 reales antes de salir de Acobamba. Al momento de su partida, Juan Luis debió pagar 496 reales a Alonso Sánchez Bustamante por la

\footnotetext{
${ }^{26}$ Unas cuentas de lo gastado en las estancias Atocsaico, Chichausiri y Chontas por López Grayño en 1667 y 1668 , dan un total de 37202 reales (o 4650 pesos con dos reales). Memoria de cuentas del señor Andrés López Grayño que entrega al cobrador de este libro, Libro de socorros de pastores de las estanzias de Hatosayco, Chichausiri y Chontas (12 de enero de 1667). Socorros de indios, leg. 1 c. (6), fs. 54-55, AAL. En 1674 -año confiable en las cuentas del pago de mitas de plata-, los empresarios adelantaron la enorme suma de 32974 reales (4 121.5 pesos) para este fin. En 1677 el monto fue de 13756 reales (1 719.5 pesos) por los 35 trabajadores del obraje de Paucartambo que ese año debían ir a Huancavelica. Libro de socorros de los yndios pastores de las estancias de San Francisco de Chichausiri y Santa Cruz de Chontas [...] para este año de 1674. Socorros de indios, leg. 2 c. (5), AAL.

${ }^{27}$ Memoria de la plata que pagué para la mita de Huancavelica de mayo-junio de 1674, la qual recibió don Pedro Tissi Huamán, gobernador de Los Reyes en una libranza que le di para Huancavelica con el qual y los indios se ajustaron estas mitas. Documento sin título 1673-1674. Socorros de indios, leg. 2 c. (3), AAL.

${ }^{28}$ Juan de Ortega era el agente de López Grayño en la estancia Llacsahuanca y don Carlos era el gobernador. Memoria de las mitas de septiembre y octubre que pagué por los yndios de la estancia de Llaxaguanca, según lo que me remitió Juan de Ortega. Documento sin título 1673-1674. Socorros de indios, leg. 2 c. (3), AAL.
} 
cuenta que tenía pendiente en su obraje de Acobamba y este dinero también fue proporcionado por López Grayño. Por el viaje se le cargaron 152 reales de flete de la ropa que pasa de un obraje al otro, pero, al perdonarle 48 reales, quedó debiendo 104 reales por este concepto. La deuda por 1292.5 reales que tenía al final del año grafica bien su situación pues en el año había logrado trabajar sólo por 109.5 reales 29

El enganche -o entrega de dinero- como anticipo para obligar a ir al trabajo es algo más frecuente en la documentación 30 En 1667, a María Sebastiana Runco le dieron 96 reales que, según las fuentes, ella misma "pidió para trabaxar el terçio que viene" en el obraje 31 En el año 1671 son dos los intentos fallidos de enganchar a mujeres para trabajar en el obraje. A María Magdalena Rapas, mujer del arriero Juan Acras, se le cargaron 80 reales que ella misma pidió "para trabaxar en el obraxe y los recibió su marido de esta yndia”. También, Juana María Vilca Huamán, hija de Juan Vilca Huamán (preso ese año en el obraje), “debe dies pesos que le di en reales para trabaxar en el obraxe, los quales recivió en su mano en quatro de março de 1672 juntamente con el dicho su padre". Ninguna de las dos llegó a trabajar y redimir las deudas, al menos en la década estudiada 32

En 1673 fueron diez los pastores que desquitaron deudas guardando ganado, pero los montos son relativamente pequeños. Más bien, en 1675 crecen los montos y dos casos son ilustrativos. Francisco Callan, indio alquilado del pueblo Vico, debe la considerable suma de 1120 reales que le dio don Antonio de la Escalera para “desquitarlos" guardando ganado. Además, su propio gobernador, Domingo Huayna Yanqui le había dado 320 reales para servir su obligación por tres meses en su cancha, en una situación que podría interpretarse como una modalidad de la mita en trabajo para el curaca. Por otro lado, 200 reales que recibió Luis Guaranga del pueblo Yanamate fueron al bolsillo del cura de Pasco. Mientras trabajaba para pagar esa deuda, Luis adquirió nuevos préstamos y adelantos. Logró descontar 195 reales con su trabajo, pero en septiembre de ese año seguía debiendo 321 reales 33

Este último caso lleva al tema, muy documentado, del endeudamiento ya estando en el trabajo. Los empresarios entregaban dinero y bienes a los trabajadores de manera sistemática para crear o incrementar una deuda que los atara y retuviera en las estancias y el obraje. Son muy frecuentes las

\footnotetext{
${ }^{29}$ Libro de los yndios pastores desta estancia de Laxaguanca a donde se les haçe el cargo y descargo de ganado que reçiven y corre desde quinçe de septiembre de mil y seisçientos y setenta y uno, con advertencia que todas las quentas de dichos pastores que an servido en esta estançia están ajustadas hasta catorce de dicho mes de septiembre de 1671 años. Socorros de indios, leg. 1 c. (10), f. 95v, AAL.

${ }^{30}$ Los obrajeros de Huamanga y del Cusco recurrieron también al trabajo de operarios endeudados para cubrir sus demandas laborales (Escandel-Tur, 1997, p. 391; Salas, 1998, vol. I, p. 441).

${ }^{31}$ Libro de socorros de pastores de las estanzias de Hatosayco, Chichausiri y Chontas desde doce de henero del año de 1667. Socorros de indios, leg. 1 c. (6), f. 22v, AAL.

${ }^{32}$ Libro de socorros de los yndios de obligación y voluntarios que trabaxan en este obraxe de la Limpia Concepción de Paucartambo deste tercio que començó a correr desde primero de mayo de mil seiscientos y setenta y uno con advertencia que començaron a trabaxar los yndios en dicho obraxe desde primero de março de dicho año por averse hecho el entero tarde por omission de los caciques [1671]. Socorros de indios, leg. 1 c. (11), fs. 143-144, AAL.

${ }^{33}$ Documento sin título 1675 [Libro de los pastores de la estancia de San Lorenzo de Atocsayco], Socorros de indios, leg. 2 c. (8), fs. $15,43,44,48,59,60 \mathrm{v}, 61$ y 62 , AAL.
} 
referencias a la entrega de dinero o bienes durante fiestas, enfermedades, casamientos y velorios, en particular en el libro manual de 1673-1674, que detalla el reparto de dinero y bienes a los trabajadores que ya laboran en el obraje 34

Además de numerosas entradas que consignan la entrega de cuartillos y reales a los indígenas, y montos mayores destinados "por junto" para la adquisición de bienes, los libros manuales registran la entrega de bienes que eran repartidos por el empresario como un antecedente de los repartos de mercancías que más adelante harían los corregidores en conjunto con comerciantes y propietarios locales, curas y curacas.

Cualquier día de la semana llegaban los productos al pueblo para ser distribuidos entre los trabajadores del obraje. Pese a ser un obraje, Paucartambo recibía grandes cantidades de "ropa de la tierra" proveniente de Jauja. Llegaban al obraje como parte de los "socorros" llicllas, bayetas, frazadas, jerga, cordellate y pañetes. Pero también llegaban vestidos de cordellate (cotones, calzones y gabardinas). La cera se repartía a 16 reales la libra para la fiesta de la Concepción o la del Rosario. Por ejemplo, el jueves santo de 1674 se repartió cera según una lista de más de cuatro páginas.

Las listas de reparto de cecinas también son largas: la del 3 de diciembre de 1673 tiene tres páginas; la de diciembre, dos; la de febrero de 1674 más de una; la de abril, tres; la de agosto, tres, y la de septiembre, dos.

En menor medida, se repartía coca, maíz, trigo, harina, aceite, tabaco en polvo, carneros, puercos, mulas, botones de Tarma, y otras mercaderías. Las tijeras y los sombreros eran un producto eventual, pero de un alto precio. Los trabajadores de las estancias debían comprar sus propias tijeras para la esquila del ganado. El 6 de junio de 1674 se repartieron, por 800 reales, 50 pares de tijeras que Tomás Muñoz de Guevara envió a Paucartambo con Pedro de Carvajal; días después, se repartieron otros 36 pares. En realidad, aquí la documentación permite establecer la diferencia en el precio entre lo que costaba al repartidor y el precio en que se repartía. López Grayño adquiría las tijeras a 16 reales el par y las repartía a 24 reales. Por otro lado, el 25 de junio se repartió a la gente del obraje 50 sombreros a 24 reales cada uno.

Menos conocido es el gasto religioso, pero su incidencia es también importante para atar a los trabajadores. López Grayño paga (o tal vez tan sólo registra) las deudas que tenían los trabajadores del obraje a favor del vicario Nicolás Martínez Pardo. Al final del libro correspondiente al periodo 1673 y 1674 se consigna la larga lista de 113 indios (89 varones y 24 mujeres) que tenían deudas por obvenciones y ofrendas, mientras que 39 indios (trece indias) debían al vicario 584 reales por limosnas llamadas de Jerusalén. A esto se deben agregar los 572 reales que por "santos" cobró el vicario al conjunto de los indios. El monto total de estas deudas asciende a 6909 reales (863 pesos con cinco reales) y, en promedio, cada trabajador debía 61 reales (o siete pesos con cuatro reales), es decir, montos muy superiores a los que debían abonar oficialmente los indígenas por concepto de tributos al rey. Esto da una idea clara de la importancia del rubro de deudas a la Iglesia dentro de los mecanismos de endeudamiento que tenía el empresario para obtener la mano de obra y retenerla en los centros de trabajo.

\footnotetext{
${ }^{34}$ Miriam Salas (1998, vol. I, p. 278) considera que este tipo de reparto era un premio a los trabajadores a quienes el obraje o las estancias debían dinero por su trabajo. El tercer tomo de su estudio contiene cuadros con información similar a la que aquí presento que demuestra el endeudamiento compulsivo de los trabajadores de los obrajes de Huamanga que ella estudia.
} 


\section{LA REMUNERACIÓN}

La remuneración de los trabajadores era variada y compleja. Incluía el dinero, pero sólo como parte de un sistema de compensación por trabajo que se hacía también en bienes y en servicios eclesiásticos, o el pago del tributo y la exoneración de las mitas. Si se considera que los salarios nominales establecidos por ley y por la práctica eran insuficientes para garantizar la subsistencia de los trabajadores, se entenderá también que el trabajo de los indígenas debía ser familiar para poder cumplir con las tareas, lo que significa que la familia del trabajador asumía parte de los costos de producción 35

No es posible establecer con precisión las proporciones en que el dinero participaba de manera efectiva en la remuneración. Sin embargo, es muy probable que el salario nominal haya sido más una medida del endeudamiento en que los trabajadores se encontraban en un momento dado respecto al empresario. En este sentido, es muy interesante que la información de un pago por trabajo que aparece como hecho en un libro, en el siguiente se señale que el pago había sido una operación contable y no efectiva. Así, en numerosos casos figura la anotación de "pagado" o hasta "pagado en mano" al final de la cuenta de un indio alquilado o mitayo, o en el título de un libro se hacía la "advertencia que todas las quentas de dichos pastores que an servido en esta estançia están ajustadas hasta catorce de dicho mes de septiembre de 1671 años”, pero luego se diga que esos montos pasan a otro libro o cuaderno de otra estancia, o del obraje de ese mismo año o de otro posterior. En realidad, el mundo rural andino maneja escasamente el dinero en efectivo (Glave, 2009, vol. II, pp. 439-441).

La remuneración de los operarios y pastores se establecía de acuerdo con el año laboral, sin incluir los domingo y días feriados. En la zona rural este tenía un poco más de 300 días y el mes laboral 22-24 días, aunque se debe considerar que el trabajo rural se regía más por el calendario agrícola de la zona.

El virrey conde de Santisteban modifica el arancel de jornales para mitayos y mingados jornaleros dado anteriormente por los virreyes Toledo y Velasco, además de que iguala el salario de los mitayos y mingados. En los obrajes de la sierra central, a los libres (mingados) se debía pagar 47 pesos con dos reales al año (cerca de un real con un cuartillo al día) más la alimentación equivalente a un real por día de trabajo; a los mitayos: 40 pesos con cuatro reales (324 reales o un real por día de trabajo), y a los muchachos: 24 pesos con dos reales (194 reales o medio real por día de trabajo, aproximadamente) (Macera, 2014, pp. 868-883).

La remuneración variaba de acuerdo con las labores que se realizaban en las estancias y el obraje como también a la condición en que se trabajaba (libre o mitayo). El indio mitayo recibía en 1668 un real por día, tal como lo mandaba el arancel del virrey conde de Santisteban, pero desde 1670 aumentó a uno y medio y hasta a dos reales diarios, sin mencionar la alimentación. Un pastor alquilado cuya obligación era guardar una o dos manadas obtenía dos reales y medio, pero podía variar en caso de cuidar carneros (96 reales al mes) o borregas ( 88 reales al mes).

\footnotetext{
${ }^{35}$ La disposición del virrey conde de Santisteban (1661-1666) establece el jornal de los pastores en dos reales más alimentación al día por cuidar una manada de no más de 660 cabezas de ovejas o corderos, pues "no pueden cumplir si no es valiéndose de sus mujeres e hijos”. Véase Macera $(2014$, p. 873).
} 
Según la documentación, el caso de los mitayos que trabajan también como alquilados es diferente, pues el cálculo se hace teniendo en cuenta el tiempo dedicado a cada modalidad. Por ejemplo, el guata (alimentador) Diego Baltasar Chucho Taquiri recibe 406 reales por nueve meses y un día como mitayo y 996 reales por un año con trece días de alquilado 36

Lo más común era que las manadas tuvieran más de 1000 cabezas, cuando lo formal era no más de 660. En 1674 sube el jornal del alquilado, pero también la carga de trabajo: ahora obtiene tres reales al día, pero debe cuidar de manera simultánea tres, cuatro, cinco y hasta seis manadas. El trabajo en estancias tenía una tarea adicional en la trasquila, pagada aparte 37

Con rebaños tan grandes, no debe llamar la atención la pérdida de grandes cantidades de cabezas de ganado 38 En los balances se hacía cargo a los pastores por las cabezas faltantes, tal vez en la creencia de que los pastores disponían del ganado de la estancia como propio durante el tiempo de su servicio, sabiendo que debían responder por las cabezas perdidas al momento de los ajustes de cuentas y que las deudas así generadas serían sumadas a sus cuentas personales ${ }^{39}$ Otra modalidad era que los mismos pastores tuvieran cabezas de su propiedad con las de la estancia. Por ejemplo, en 1669 se le cobraron 80 reales al indio alquilado Gaspar Antonio Jaico por "acomodar su ganado en Ullucmayo", en una suerte de antecedente de los huacchilleros que Joan Martínez

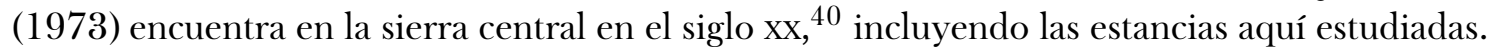

\footnotetext{
${ }^{36}$ Libro de los yndios pastores desta estancia de Laxaguanca [...] de 1671 años. Socorros de indios, leg. 1 c. (10), fs. $4,5,9,13,39 \mathrm{v}-42 \mathrm{v}, 60,69,70,77$, AAL.

${ }^{37} \mathrm{El}$ indio alquilado Juan Cóndor (Ninacaca, ayllu colca) ya trabaja en Llacsahuanca, y en septiembre de 1671 recibe 1289 ovejas, 100 carneros padres y 973 corderos. En abril del año siguiente le quitan la manada (1 199 ovejas madres, 295 borregas, 43 carneros padres y 882 corderos), reclamándole por siete ovejas madres, un padre y 40 corderos faltantes. En agosto del mismo año le entregan una nueva manada: 1117 ovejas madres, 74 carneros padres y 1257 corderos, pero luego de menos de dos semanas cuentan el ganado y faltaban dos corderos, en septiembre de 1673 cuentan nuevamente 1938 cabezas y afirman que debía cuatro madres. Después de dos años, y con Juan fallecido, se establece que junto a su hijo Alonso Cóndor trabajó ocho meses y diez días como alquilado a razón de 80 reales el mes (664 reales) más 148 reales por la trasquila, pero debía 208 reales por cabezas no devueltas. Libro de los yndios pastores desta estancia de Laxaguanca [...] de 1671 años. Socorros de indios, leg. 1 c. (10), fs. 11-11v, AAL.

${ }^{38}$ Un siglo después, en 1786, el intendente de Tarma informa al gobierno que encontró esta práctica todavía vigente en Bombón. Dice que él ordenó que las manadas no sobrepasaran las 600 cabezas para evitar la "oprecion tirana e iniqua" de parte de los estancieros (Arellano, 1984, p. 36).

${ }^{39}$ En las cuentas de 1667 figuran tres casos en los que pastores deben dinero por no haber devuelto varias cabezas, pero en el ajuste hecho en agosto de 1668, fueron quince los pastores de Llacsahuanca que debían por ganado y, además, los montos adeudados por este rubro se elevan considerablemente. En conjunto, los quince pastores deben 2275.5 reales por pérdidas (lo que equivalía a 568 carneros o 380 ovejas). Con 587.5 reales, el mayor perdedor de ganado ese año es Hernando Chaccha Huamán: 53 ovejas y 151 corderos. En 1670 seis pastores arrastran aún deudas por 1516.5 reales por este concepto.

${ }^{40}$ Documento sin título [Libro de pagos. Obraje de Paucartambo, 1669]. Socorros de indios, leg. 1 c. (1), f. 53v, AAL. El huacchillero es un pastor propietario de ganado que pasta con el ganado de la estancia, aunque en condición subordinada. Véase Pozo-Vergnes (2004). Según Bernardino Ramírez Bautista, los pastores eran engañados al momento de hacer las cuentas y terminaban debiendo más cabezas de ganado de las que habían perdido, y así tenían que trabajar más tiempo para el hacendado. Sobre Pasco, véase Ramírez (2002).
} 
El trabajo en el obraje se organizaba a destajo. La tarea era la medida de la remuneración de los operarios tanto voluntarios como mitayos, y era pagada a razón de un real cada una, y debía corresponder a una jornada laboral ${ }^{41}$ Las tareas extraordinarias se hacían para las wairas o "salidas de chacras". En 1677 todo hace suponer que se incrementa la carga laboral en el obraje. Al menos, así lo muestra el aumento de las cifras de tareas cumplidas por los operarios 42

\section{Los balances o “ajustes” de las cuentas}

Los balances o "ajustes" se realizaban sin una periodicidad fija. En este acto participaban los curacas como representantes de los indígenas de sus pueblos e, incluso, al menos en algunos casos, ellos cobraban el dinero que resultaba del trabajo de los miembros de sus comunidades que remitían a los empresarios de haciendas y obrajes, y que debían guardar en la caja de la comunidad para afrontar las obligaciones colectivas (tributos, fiestas, etc.) y cubrir los aportes de los ausentes.

La compulsa entre las cargas y el pago que recibían los trabajadores en el lapso estudiado ayuda a comprender mejor este fenómeno que esconde mucho en las cuentas. En particular, sería importante determinar si -como todo hace pensar- la dinámica entre las deudas adquiridas ya trabajando ("nuevos cargos") y lo redimido en el trabajo era parte consustancial de un sistema de remuneraciones que buscaba pagar en especie (productos) y servicios (sustitución de tributos y mitas) antes que en dinero y que seguía una lógica de un endeudamiento adelantado que resultara difícil o, incluso, imposible de eliminar.

Los pastores de las cuatro estancias en su conjunto debían cantidades tan elevadas que era imposible cubrirlas con su trabajo regular. El caso de 1671 -año con datos más confiables- muestra que, incluso con una cifra alta en salarios, se queda debiendo 31760 reales (casi 4000 pesos).

Ya de manera individual, una constatación muy importante es que los montos de las nuevas deudas se han más que duplicado pues, en promedio, un pastor empezaba el trabajo debiendo 422 reales en 1667, 393 reales en 1671 y 1195 reales en 1674, y al hacer el ajuste al final del periodo tenía una deuda de 471 reales en 1667, 481 reales en 1671 y 1208 reales en 1674 , lo que disminuía su capacidad para redimir los "socorros" recibidos como adelanto, pues lo obtenido por salarios, que en 1667 era de 380 reales en promedio, había subido a 819 reales en 1671 y luego bajado a 630 reales en 1674 (véase cuadro 7).

Numerosos trabajadores salían del trabajo más endeudados de lo que lo estaban al iniciar sus labores. Como ejemplo, Pedro Ayacsongo entró en enero de 1673 a cuidar cinco manadas y, luego de haber trabajado 30 meses a 88 reales el mes, el cómputo de su salario fue de 2640 reales que de poco le sirvieron pues en el mismo lapso sus deudas crecieron tanto que debía 950 reales en diciembre de 1675. Lo mismo sucedió con Ignacio Poma Chagua, que había trabajado 30 meses para terminar debiendo 1676 reales, Pedro Atau Páucar debía 1091 reales como ayudante en el ahijadero, Pedro Rupay Malqui debía 1666.5 reales, Juan Malqui Chagua quedó debiendo

${ }^{41}$ En los obrajes del Cusco la tarea del mitayo se pagaba también a un real en el siglo XVII y a dos reales en el XVIII. A los indios alquilas se les abonaba dos reales en dinero y medio real en chicha al día, pagados al curaca (EscandellTur, 1997, pp. 386 y 407). En los obrajes de Huamanga se exigían tres tareas mensuales por 24 reales (Salas, 1998, I, pp. 247-248).

${ }^{42}$ Libro de socorros de los yndios que travajan boluntariamente en este obraxe de la Limpia Concepción de Paucartambo en este tercio que empezó a correr desde oi lunes 24 de mayo de 1677 años. Empezase a asentar lo que se les da a los yndios de socorros mitas y tributos desde 18 de mayo deste dicho año en este libro por aver corrido el pasado hasta 17 de mayo de dicho año de 1677. Digo que se empezó a asentar desde 18 de junio de 1677 años por aver corrido el otro libro asta 17 de junio de 1677 años. Socorros de indios, leg. 2 c. (7), AAL. 


\section{CUADRO 7. RESUMEN DE CARGOS, SALARIOS Y DEUDAS DE LOS INDIOS PASTORES DE LAS ESTANCIAS, 1667-1674 (EN REALES)}

\begin{tabular}{lccccc}
\hline Año & $\begin{array}{l}\text { Deuda } \\
\text { previa }\end{array}$ & $\begin{array}{c}\text { Nuevos } \\
\text { cargos }\end{array}$ & Salario & Deuda & Acreencia \\
\hline 1667 & 14761 & 45161 & 28137 & 34889 & 5740 \\
1671 & 10220 & 71456 & 54057 & 31760 & 4133 \\
1674 & 27480 & 19026 & 17003 & 32628 & 3215 \\
\hline
\end{tabular}

Fuente: elaboración propia con base en Socorros de Indios, años 1667-1677, 2 legajos, AAL.

1765.5 reales, Diego Chagua debía 2631.5 reales luego de cuidar seis manadas en ese tiempo, Domingo Huamán Chaca debía 3662 reales por las seis manadas que cuidó, Andrés Chagua debía 2515.5 reales, Diego Quispe Huamán debía 296 reales, Diego Ticsi Chagua Yanaqueso debía 4105.5 reales por cinco manadas, incluyendo un mes en el preñadero a 100 reales mensuales, pero recibiendo sólo 80 reales 43

Las cifras de las deudas que las estancias tenían a favor de los pastores por trabajo eran trasladadas a los nuevos libros. Las acreencias se producen pues hubo pastores que, lejos de endeudarse, debían recibir dinero en efectivo de parte de la empresa ganadera.

En el obraje la situación era incluso peor que en las estancias, pues en su conjunto los operarios arrastran montos mucho más grandes. Las deudas anteriores se incrementan hasta cuadruplicarse o más en la década y duplicarse entre 1671 y 1677. En realidad, sólo en 1669 y 1677 los salarios cubrieron los endeudamientos adquiridos ya estando en el trabajo. De ahí la importancia de los endeudamientos para fijar a los trabajadores en el obraje, pues los pueblos no eran ya suficientes para este propósito. Como en el caso de las estancias, existieron operarios que terminaron su trabajo con deudas a su favor que, por lo regular, la empresa trasladó al libro siguiente en vez de cancelar en mano como estaba mandado.

El incremento de deudas individuales en el obraje es muy notorio a lo largo de la década de estudio. Si al inicio existen sólo dos operarios con deudas a pagar por el equivalente a 960 tareas o más, en 1677 ya son siete los que deben trabajar más de tres años para cancelar lo adeudado; y de cinco operarios endeudados con montos superiores a 480 reales en 1667, diez años después ya eran 31 los que debían trabajar un año y medio sólo para salir de las deudas (véase cuadro 8).

También existieron los casos de endeudamiento moderado, pero casi todos los casos documentados se refieren a pastores y operarios del obraje eventuales. Incluso, da la impresión de que trabajan sólo para librarse de una deuda ocasional. Por ejemplo, en 1667 Fernando Coya Chagua incurrió en una deuda de 60 reales que pudo eliminar con los 167 reales de su corto trabajo. Lo mismo sucedió con Felipe de la Cruz Solano, quien canceló 36 reales que debía y, al parecer, no se interesó por seguir trabajando en la estancia, trasladándose a trabajar en el obraje de Paucartambo. Francisco Carlos hizo lo propio en 1671, ya que, con una deuda de 42 reales, trabajó y reportó 174 reales; Agustín Gregorio debía 98 reales, pero trabajó por 254, y Juan Yacolca debía 29, pero ganó 120 reales.

\footnotetext{
${ }^{43}$ Libro de socorros de los yndios pastores de las estancias de San Francisco de Chichausiri y Santa Cruz de Chontas [...] para este año de 1674. Socorros de indios, leg. 2 c. (5), fs. 1- 7, 9-14, 16, 17, 19, 21 , 23 y 25, AAL.
} 


\section{CUADRO 8. RESUMEN DE CARGOS, SALARIOS Y DEUDAS DE LOS INDIOS OPERARIOS DEL OBRAJE, 1667-1674 (EN REALES)}

\begin{tabular}{lcccrr}
\hline$\cdot$ & $\begin{array}{l}\text { Deuda } \\
\text { previa }\end{array}$ & $\begin{array}{c}\text { Nuevos } \\
\text { cargos }\end{array}$ & Salario & Deuda & Acreencia \\
\hline 1667 & 32999 & 30459 & 27325 & 39356 & 3407 \\
1669 & 80272 & 32933 & 48017 & 74608 & 11496 \\
1671 & 70895 & 66858 & 49782 & 94187 & 5851 \\
1677 & 136498 & 52247 & 52793 & 130792 & 5219 \\
\hline
\end{tabular}

Fuente: elaboración propia con base en Socorros de Indios, años 1667-1677, 2 legajos, AAL.

\section{Conclusiones}

La década de estudio (1667-1677) muestra que el régimen de reducciones toledanas quedó obsoleto en Bombón, ya que un siglo después de la creación de reducciones o pueblos de indios la mita estanciera y obrajera resulta muy insuficiente para cubrir las necesidades laborales de las empresas privadas aparecidas en la zona en las décadas anteriores. En tiempos en que la población estaba en sus niveles demográficos más bajos, cambiaron las relaciones entre los pueblos y los empresarios de las cuatro estancias ganaderas y el obraje. El reto consistía en lograr captar y retener a los indígenas que vivían en los pueblos, pero no como originarios, sino como forasteros, pues esta población no obedecía a los mecanismos tradicionales (toledanos), y las exigencias fueron mucho mayores con la consolidación de empresas privadas en un mercado colonial en expansión.

La escasez de trabajadores potenciales hace pensar que la misma favorecía a estos al negociar las condiciones de los acuerdos laborales. Sin embargo, los hechos muestran: $a$ ) compromisos del empresario con los curacas de los pueblos sobre las parcialidades que van más allá del orden toledano de mitas para abastecer de mano de obra a las empresas privadas (haciendas, obrajes, minas, etc.), bajo un régimen de solidaridad corporativa a cambio de recursos monetarios que cubren las urgencias coloniales de la comunidad en su conjunto, y $b$ ) mecanismos de endeudamiento individual que se valen de las cargas coloniales ya existentes (tributos y mitas), pero añadiendo obligaciones nuevas y más demandantes.

Según los documentos, los pueblos y curacas ya no son suficientes para garantizar el funcionamiento de las actividades privadas ubicadas en el entorno (o incluso dentro) de las comunidades y, por esto, se introducen mecanismos también compulsivos, pero basados en un control individual (deudas) para contrarrestar la resistencia al incremento de turnos de mitas, la duplicación de los tributos, la elevación de las tareas tanto en las estancias como en el obraje, la sustitución de la mita minera en Huancavelica por la mita de plata en Bombón, el sistema (todavía rudimentario) de reparto de mercaderías entre los trabajadores y el cobro que hace la empresa por servicios eclesiásticos.

A pesar del aumento de las remuneraciones nominales, la evidencia cuantitativa y cualitativa marca un deterioro de las condiciones de trabajo y la remuneración de los trabajadores medible en los niveles de endeudamiento en que incurren y que los obliga a dedicar mayor tiempo propio y de familiares a las labores en las estancias y el obraje. Una importante parte de la población 
indígena está al borde de la yanaconización por quedar en el desamparo respecto a las instituciones tradicionales andinas, estando como estaba endeudada por montos superiores al equivalente a un año y medio de trabajo gratuito.

En efecto, la mitad de los 596 trabajadores del complejo ganadero y textil fue reclutada en los pueblos de la meseta según el orden toledano, mientras que la otra mitad llegó de otros lugares (incluso de los mismos pueblos, pero en su condición de indios forasteros) a través de mecanismos coercitivos que incluyeron obligaciones coloniales que ya se daban, como el tributo y la mita estanciera y obrajera, pero a las que ahora se suman obvenciones eclesiásticas, la mita de plata a favor de los propietarios mineros de Huancavelica, adelantos de dinero, el pago en productos alimenticios (sal, coca, maíz, trigo, harina, aceite, cecinas y carnes), además de la entrega compulsiva de bienes como un antecedente del reparto de mercaderías que luego se generalizaría en los Andes ya con la participación de los corregidores y comerciantes. Aunque las dos terceras partes de los 1151 registros de trabajo se refieren a los llamados indios alquilados (mingados, varones y mujeres formalmente libres), se trata de modalidades de regímenes laborales basados en vínculos extraeconómicos toda vez que el "salario" funcionaba como un referente de las deudas y acreencias que tienen el empresario y sus trabajadores.

Por su parte, el empresario no pudo conseguir la participación laboral directa y masiva de las mujeres de los pueblos. Sin obligaciones coloniales formales, las mujeres tuvieron que ser atraídas a través del endeudamiento que, en su caso, no alcanzó niveles tan altos como entre los varones. Más bien, las mujeres cumplen el papel de cubrir turnos de trabajo de sus parientes varones a fin de lograr aminorar o eliminar las deudas adquiridas que, en este caso, son deudas familiares pues se heredan por generaciones.

Todo esto lleva a una nueva configuración de regímenes laborales coercitivos que tendrán vigencia durante las centurias siguientes en los Andes, incluso más allá de los límites temporales del periodo colonial, aspecto que bien merecería la atención de estudiosos sobre otros lugares y actividades económicas, a fin de establecer la medida en que se pueden generalizar los hallazgos obtenidos en este estudio.

Este es, en suma, un estudio detallado de los mecanismos que aplicó un empresario ganadero y obrajero para reclutar, mantener y utilizar la mano de obra de los pueblos indígenas de los alrededores, que muestra una realidad que apunta a un claro empeoramiento de las condiciones de vida y de trabajo de la población indígena, que incluso asume con sus familias los costos de reproducción de la mano de obra de haciendas, minas y obrajes privados en tiempos en que se inicia el apogeo de la producción ganadera y textil en los obrajes de los Andes centrales, de acuerdo con dinámicas propias de un mercado interno colonial en expansión.

\section{LISTA DE REFERENCIAS}

Allen, R. C., Murphy, T. E. y Schneider, E. B. (2012). The colonial origins of the divergence in the Americas: a labor market approach. The Journal of Economic History, 72(4), 863-894. DOI: $10.1017 / \mathrm{S} 0022050712000629$

Arellano, C. (1984). Notas sobre el indígena en la intendencia de Tarma. Una evaluación de la visita de 1786. Bonn: Seminar für Völkerkunde.

Ares, B., y Stella, A. (eds.) (2000). Negros, mulatos, zambaigos: derroteros africanos en los mundos ibéricos. Sevilla: Escuela de Estudios Hispano-Americanos/Consejo Superior de Investigaciones Científicas. 
Arroyo, L., Davies, E. y Zanden, J. L. (2012). Between conquest and independence: Real wages and demographic change in Spanish America, 1530-1820. Explorations in Economic History, 49(2), 149-166. DOI: 10.1016/j.eeh.2011.12.001

Bardales, A. E. (2016). Idolatría y resistencia indígena. El caso de Santiago de Maray (1677-1678) (Tesis de licenciatura). Universidad Nacional Mayor de San Marcos, Lima.

Brown, J. C. (2000). Latin America: a social history of the colonial period. Fort Worth: Harcourt College Publishers.

Burga, M., y Manrique, N. (1990). Rasgos fundamentales de la historia agraria peruana, siglos Xvi-Xx. En A. Chirif, N. Manrique y B. Quijandría (eds.), Perú: el problema agrario en debate (pp. 23-61). Lima: SEPIA III/Centro de Estudios Regionales Andinos Bartolomé de las Casas.

Bush, M. L. (1996). Serfdom and slavery: studies in legal bondage. Londres: Longman.

Cole, J. A. (1985). The Potosi mita, 1573-1700: compulsory Indian labor in the Andes. Stanford: Stanford University Press.

Cook, N. D. (2010). La catástrofe demográfica andina Perú, 1520-1620. Lima: Pontificia Universidad Católica del Perú.

Concejo Provincial de Lima (1935). Libros de Cabildos de Lima. Lima: Autor.

Dell, M. (2010). The persistent effects of Peru's mining mita. Econometrica, 78(6), 1863-1903. DOI: 10.3982 /ECTA8121

Dobado, R. y García, H. (2014). Neither so low nor so short: wages and heights in Bourbon Spanish America from an international comparative perspective. Journal of Latin American Studies, 46(2), 291-321. DOI: 10.1017/S0022216X14000054

Engerman, S. L. (ed.) (1999). Terms of labor: Slavery, serfdom, and free labor. Stanford: Standford University Press.

Engerman, S. y Sokoloff, K. (2005). Colonialism, inequality, and long-run paths of development (Documento de Trabajo, NBERw 1 1057). Cambridge: National Bureau of Economic Research. DOI: $10.3386 / \mathrm{w} 11057$

Escandell-Tur, N. (1997). Producción y comercio de tejidos coloniales: los obrajes y chorrillos del Cusco, 1570-1820. Cusco: Centro de Estudios Regionales Andinos Bartolomé de Las Casas.

Glave, L. M. (2009). Propiedad de la tierra, agricultura y comercio, 1570-1700: el gran despojo. En C. Contreras, Compendio de historia económica del Perú (vol. II, pp. 313-446). Lima: Banco Central de Reserva del Perú/Instituto de Estudios Peruanos.

Graubart, K. B. (2007). With our labor and sweat: indigenous women and the formation of colonial society in Peru, 1550-1700. Stanford: Stanford University Press.

Hurtado, C. H. (2006). Curacas, industria y revuelta en el valle del Mantaro, siglo XVIII. Lima: Consejo Nacional de Ciencia, Tecnología e Innovación Tecnológica.

Lazo, C. y Tord, J. (2007). Historia de la economía colonial: hacienda, comercio, fiscalidad y luchas sociales (Perú colonial). En C. Lazo y J. Tord, Obras escogidas de Carlos Lazo García (vol. II). Lima: Fondo Editorial del Pedagógico San Marcos.

León, M. (2002). Paños e hidalguía: encomenderos y sociedad colonial en Huánuco. Lima: Instituto de Estudios Peruanos.

Macera, P. (2014). Obras escogidas de historia. Lima: Congreso del Perú.

Martínez, J. (1973). Los huacchilleros del Perú. Dos estudios de formaciones sociales agrarias. París: Instituto de Estudios Peruanos/Ruedo Ibérico.

Miño, M. (1993). La protoindustria colonial hispanoamericana. México: El Colegio de México. 
Mumford, J. (2012). Vertical empire: The general resettlement of Indias in the colonial Andes. Durham: Duke University Press.

Povea, I. M. (2014). Minería y reformismo borbónico en el Perú: estado, empresa y trabajadores en Huancavelica, 1784-1814. Lima: Banco Central de Reserva del Perú/Instituto de Estudios Peruanos.

Pozo-Vergnes, E. (2004). De la hacienda a la mundialización: sociedad, pastores y cambios en el altiplano peruano. Lima: Instituto Francés de Estudios Andinos: Instituto de Estudios Peruanos.

Proctor, F. T. (2003). Afro-mexican slave labor in the obrajes de panos of New Spain, seventeenth and eighteenth centuries. The Americas, 60(1), 33-58. DOI: 10.1353/tam.2003.0079

Puente, J. de la y Janssen, F. (1997). Encomienda y riqueza en una zona marginal del Perú: el caso de Chinchaycocha (siglos XVI-XVII). Histórica, 21(1), 111-134.

Quiroz, E. y Bonnett, D. (eds.) (2009). Condiciones de vida y de trabajo en la América colonial: legislación, prácticas laborales y sistemas salariales. Bogotá: Universidad de Los Andes/CEso.

Quiroz, F. (2010). Industria urbana y rural en el Perú colonial tardío. En C. Contreras (ed.), Compendio de historia económica del Perú (vol. 3. Economía del periodo colonial tardío, pp. 169-222). Lima: Banco Central de Reserva del Perú/Instituto de Estudios Peruanos.

Quiroz, F. (2016). La moneda en el mercado interno peruano colonial. En C. Contreras (ed.), Historia de la moneda en el Perú (pp. 199-226). Lima: Banco Central de Reserva de Perú/Instituto de Estudios Peruanos.

Ramírez, B. (2002). Pasco rural: modernización del latifundio Algolan y la subsistencia de la comunidad ganadera pasqueña. Rancas: Municpalidad Distrital Simón Bolívar.

Saitō, A. y Rosas, C. (eds.) (2017). Reducciones: la concentración forzada de las poblaciones indígenas en el virreinato del Perú. Japón-Perú: National Museum of Ethnology/Pontificia Universidad Católica del Perú.

Salas, M. (1998). Estructura colonial del poder español en el Perú: Huamanga (Ayacucho) a través de sus obrajes: siglos XVI-XVIII (vol. I). Lima: Pontificia Universidad Católica del Perú, Fondo Editorial.

Silva Santiesteban, F. (1964). Los obrajes en el virreinato del Perú. Lima: Museo Nacional de Historia.

Tandeter, E. (1992). Coacción y mercado: la minería de la plata en el Potosí colonial, 1692-1826. Cusco: Centro de Estudios Regionales Andinos Bartolomé de las Casas.

Zuloaga, M. (2012). La conquista negociada: guarangas, autoridades locales e imperio en Huaylas, Perú (1532-1610). Lima: Instituto Francés de Estudios Andinos/Instituto de Estudios Peruanos.

Archivos

AAL Archivo Arzobispal de Lima. 